OPEN ACCESS

Edited by:

Urs Feller,

University of Bern, Switzerland

Reviewed by:

Rosario Vera-Estrella,

National Autonomous University of Mexico, Mexico

Guzel Kudoyarova,

Institute of Biology (CAS), Russia

${ }^{*}$ Correspondence:

Bingjun Yu

bjyu@njau.edu.cn

Specialty section:

This article was submitted to Agroecology and Land Use Systems,

a section of the journal

Frontiers in Plant Science

Received: 27 April 2017

Accepted: 29 June 2017

Published: 17 July 2017

Citation:

An J, Hu Z, Che B, Chen H, Yu B and Cai W (2017) Heterologous Expression of Panax ginseng PgTIP1

Confers Enhanced Salt Tolerance of Soybean Cotyledon Hairy Roots, Composite, and Whole Plants.

Front. Plant Sci. 8:1232. doi: 10.3389/fpls.2017.01232

\section{Heterologous Expression of Panax ginseng PgTIP1 Confers Enhanced Salt Tolerance of Soybean Cotyledon Hairy Roots, Composite, and Whole Plants}

\author{
Jing $A n^{1}$, Zhenmin $\mathrm{Hu}^{1}$, Benning $\mathrm{Che}^{1}$, Haiying $\mathrm{Chen}^{2}$, Bingjun $\mathrm{Yu}^{1 *}$ and Weiming Cai ${ }^{2}$ \\ ${ }^{1}$ Laboratory of Plant Stress Biology, College of Life Sciences, Nanjing Agricultural University, Nanjing, China, ${ }^{2}$ Institute of \\ Plant Physiology and Ecology, Shanghai Institutes for Biological Sciences, University of Chinese Academy of Sciences, \\ Chinese Academy of Sciences, Shanghai, China
}

The Panax ginseng TIP gene PgTIP1 was previously demonstrated to have high water channel activity by its heterologous expression in Xenopus laevis oocytes and in yeast; it also plays a significant role in growth of PgTIP1-transgenic Arabidopsis plants under favorable conditions and has enhanced tolerance toward salt and drought treatment. In this work, we first investigated the physiological effects of heterologous PgTIP1 expression in soybean cotyledon hairy roots or composite plants mediated by Agrobacterium rhizogenes toward enhanced salt tolerance. The PgTIP1-transgenic soybean plants mediated by the pollen tube pathway, represented by the lines $N$ and $\mathrm{J11}$, were analyzed at the physiological and molecular levels for enhanced salt tolerance. The results showed that in terms of root-specific heterologous expression, the PgTIP1transformed soybean cotyledon hairy roots or composite plants displayed superior salt tolerance compared to the empty vector-transformed ones according to the mitigatory effects of hairy root growth reduction, drop in leaf RWC, and rise in REL under salt stress. Additionally, declines in $\mathrm{K}^{+}$content, increases in $\mathrm{Na}^{+}$content and $\mathrm{Na}^{+} / \mathrm{K}^{+}$ratios in the hairy roots, stems, or leaves were effectively alleviated by PgTIP1-transformation, particularly the stems and leaves of composite soybean plants. At the whole plant level, PgTIP1-trasgenic soybean lines were found to possess stronger root vigor, reduced root and leaf cell membrane damage, increased SOD, POD, CAT, and APX activities, steadily increased leaf Tr, RWC, and Pn values, and smaller declines in chlorophyll and carotenoid content when exposed to salt stress compared to wild type. Moreover, the distribution patterns of $\mathrm{Na}^{+}, \mathrm{K}^{+}$, and $\mathrm{Cl}^{-}$in the roots, stems, and leaves of saltstressed transgenic plants were readjusted, in that the absorbed $\mathrm{Na}^{+}$and $\mathrm{Cl}^{-}$were mainly restricted to the roots to reduce their transport to the shoots, and the transport of root-absorbed $\mathrm{K}^{+}$to the shoots was simultaneously promoted. PgTIP1 transformation into soybean plants enhanced the expression of some stress-related genes (GmPOD, GmAPX1, GmSOS1, and GmCLC1) in the roots and leaves under salt treatment. 
This indicates that the causes of enhanced salt tolerance of heterologous PgTIP1transformed soybean are associated with the positive regulation on water relations, ion homeostasis, and ROS scavenging under salt stress both at root-specific and whole plant levels.

Keywords: PgTIP1 transformation, salt tolerance, soybean hairy roots, transgenic soybean, water relations, ion homeostasis, ROS scavenging

\section{INTRODUCTION}

Aquaporins (AQPs) are integral or intrinsic channel proteins with molecular weights of 21 to $34 \mathrm{kD}$ and a conserved structure. They locate in the plasma and intracellular membranes of plant cells, where they facilitate the transport of water and/or a wide range of small neutral or uncharged solutes (glycerol, urea, boric acid, silicic acid, arsenite, ammonia, $\mathrm{CO}_{2}$, and $\mathrm{H}_{2} \mathrm{O}_{2}$, etc.) (Katsuhara et al., 2008; Maurel et al., 2008; Chaumont and Tyerman, 2014; Srivastava et al., 2014; Tian et al., 2016; Wang et al., 2016). Based on sequence homology or similarity, subcellular localization, and expression patterns, plant AQPs can generally be classified into five subfamilies: plasma membrane intrinsic proteins (PIPs), tonoplast intrinsic proteins (TIPs), nodulin26-like intrinsic proteins (NIPs), small and basic intrinsic proteins (SIPs), and uncategorized X intrinsic proteins (XIPs) (Kaldenhoff and Fischer, 2006; Danielson and Johanson, 2008). AQPs (mostly PIPs and TIPs) can provide plants with the means to rapidly and reversibly modify water permeability across cell membranes, and play a crucial role in plant water relations or homeostasis during plant growth, development, and even stress adaptation through the regulation of root water uptake or transport, leaf transpiration, or loss mediated by root and leaf hydraulic conductivity (Maurel et al., 2008; Chaumont and Tyerman, 2014). Furthermore, there is communication between apoplastic and intracellular reactive oxygen species (ROS) pools through certain AQPs (Dietz et al., 2016). For example, $\mathrm{H}_{2} \mathrm{O}_{2}$ is a relatively stable component of ROS compared with other ROS molecules, such as the superoxide anion radical $\left(\mathrm{O}_{2}^{\bullet-}\right)$, and the production of $\mathrm{H}_{2} \mathrm{O}_{2}$ is typically apoplastic, resulting mainly from PM-located NADPH oxidase that catalyzes $\mathrm{O}_{2}^{\bullet-}$ formation which is then converted to $\mathrm{H}_{2} \mathrm{O}_{2}$ either spontaneously or by extracellular superoxidase (SOD). $\mathrm{H}_{2} \mathrm{O}_{2}$ can function as an important secondary messenger in signal transduction networks involved in the plant response under favorable and stressful environments (Saxena et al., 2016; Tian et al., 2016). Tian et al. (2016) suggested a pivotal role for an Arabidopsis aquaporin (AtPIP1;4) in the importing of extracellular $\mathrm{H}_{2} \mathrm{O}_{2}$ into the cytoplasm for apo-cytoplastic signal transduction and in activating responses for disease immunity or resistance.

At present, plants or crops often suffer from many abiotic (salt, drought, low temperature, heat, etc.) and biotic (disease, insects, weeds, etc.) stresses during their growth and development, and this appears to be growing in frequency as a result of global climate warming, severely restricting the development of modern sustainable agriculture (Rouached et al., 2015). Under a variety of adverse environments, AQPs may have positive (such as increasing root water uptake and reducing leaf water loss) or negative effects across different plant species, stress types, and intensity of the adversity. Additionally, the mechanisms by which AQPs regulate plant water relations or homeostasis are particularly complicated due to the diverse classes and functions for AQPs themselves. As a result of this, researchers often choose one or several particular interesting AQP members in a certain plant to conduct concentrated and systematic studies on the physiological and molecular functions, particularly focusing on adaptation to unfavorable conditions. Various biological analytical assays, such as Xenopus laevis oocytes, yeast expression systems, mesophyll protoplast, and even transgenic plants have been adopted for highlighting the beneficial functions of AQPs on plant water homeostasis and stress adaptation (Deshmukh et al., 2016). Many researches have now suggested that the differential (down- or up-regulated) transcriptional expression of AQP genes, especially for both PIPs and TIPs, and changes in AQP density through endomembrane trafficking and activity including posttranslational modifications, protein interaction, and subcellular relocalization are essential for plant water homeostasis, playing crucial roles in plant growth, development, and stress adaptation (Boursiac et al., 2005; Lin et al., 2007; Maurel et al., 2008; Wudick et al., 2009; Chaumont and Tyerman, 2014). A coordinated transcriptional down-regulation of certain PIPs and TIPs was found in Arabidopsis roots exposed to salt treatment, and may prevent deleterious effects from excessive salt uptake (Boursiac et al., 2005).

The TIP gene PgTIP1, which was found to be highly and specifically expressed in hormone-autotrophic ginseng cells, was demonstrated to have high water channel activity by its heterologous expression in Xenopus laevis oocytes with regards to the cell volume-changing rate, as well as in yeast by means of a protoplast bursting assay. It was also shown to have a significant role in the growth and development of PgTIP1-transgenic Arabidopsis plants under favorable conditions, including enhanced seed size and mass, and higher fatty acid content than the wild-type control (Lin et al., 2007; Li and Cai, 2015). Another related study by Peng et al. (2007) reported that the overexpression of PgTIP1 in transgenic Arabidopsis plants led to enhanced tolerance against salt and drought stress, but lowered cold acclimation ability. Further work by $\mathrm{Li}$ and Cai (2015) suggested that the conferred faster growth and enhanced salt tolerance in transgenic Arabidopsis plants was related to its water channel activity of the Ser ${ }^{128}$ residue of PgTIP1. Functional analyses using the plant $P g T I P 1$-transgenic technique have predominantly focused on Xenopus laevis oocytes, yeast, or non-crop Arabidopsis, whereas related studies on crops have rarely been reported. Of these crops, soybean (Glycine max L.) is the world's leading economic oilseed crop and is also a 
major source of human food and animal feed (Manavalan et al., 2009). Although soybean is classified as a moderately $\mathrm{NaCl}$ tolerant plant, the conventional breeding of soybean cultivars for improved salt tolerance is challenging due to its narrow basis of genetic germplasm and relatively limited salt tolerance (Li et al., 2006; Zhang et al., 2011). To date, about 70 AQP members have been discovered across the entire soybean genome, of which 23 are TIPs (Zhang et al., 2013; Deshmukh et al., 2016; Song et al., 2016). Wang et al. (2011) reported Arabidopsis plants overexpressing GsTIP2;1 from G. soja displayed reduced tolerance to salt and drought stress when dehydration speed or water loss in the plant was enhanced. Song et al. (2016) studied the solute transport function of two soybean TIPs (GmTIP1;5 and GmTIP2;5) by expression in Xenopus laevis oocytes, and found that GmTIP1;5 facilitated the rapid movement of water across the oocyte membrane, while GmTIP2;5 facilitated the movement of water and boric acid. Thus, different types of TIP-encoded proteins in plants display diverse selectivity for substrate and various stress responses to salt and drought. Consequently, research on the effects and physiological and molecular mechanisms of PgTIP1 expression in widely cultivated crops such as soybean to improve tolerance of saline conditions, as well as the exploration of PgTIP1 heterologous expression for obtaining new transgenic plant germplasms and salt-tolerant crop varieties, seems very necessary. The theoretical potential and practical application should be explored.

In this work, we used the globally cultivated salt-tolerant soybean cultivar Lee68 as the experimental material and investigated the physiological enhancement toward salt tolerance of heterologous PgTIP1 expression in soybean cotyledon hairy roots and composite plants mediated by $A$. rhizogenes. We then selected our local soybean cultivar Nannong 8831 as a

TABLE 1 | Primers for RT-PCR of the stress-related genes.

\begin{tabular}{|c|c|c|c|}
\hline Gene names & Accession no. & & Primer sequences $\left(5^{\prime} \rightarrow 3^{\prime}\right)$ \\
\hline \multirow[t]{2}{*}{ GmTIP1;1 } & AK285481 & $\mathrm{F}$ & TGGAGTCGGAGTTGGCAAC \\
\hline & & $\mathrm{R}$ & GTGTGGCTGATGAAGACAACC \\
\hline \multirow[t]{2}{*}{ GmTIP1;3 } & NM_001255778 & $\mathrm{F}$ & TCGTCTACGTCATCGCC \\
\hline & & $\mathrm{R}$ & AACCTCGTAGATAAGCCCAG \\
\hline \multirow[t]{2}{*}{ GmSOD1 } & NM_001248369 & $\mathrm{F}$ & CGTAACTGGATCTCTTGCTG \\
\hline & & $\mathrm{R}$ & CAGAATCAGCATGGACAACA \\
\hline \multirow[t]{2}{*}{ GmCAT1 } & NM_001250627 & $\mathrm{F}$ & AAGTGTGCCCATCACAACAATC \\
\hline & & $\mathrm{R}$ & AGAACGATCAGCCTGAGACC \\
\hline \multirow[t]{2}{*}{ GmPOD } & NM_001251386 & $\mathrm{F}$ & TGCTITGTTCAAGGTTGTGA \\
\hline & & $\mathrm{R}$ & CTCAGGTCCAAATTGGTGAG \\
\hline \multirow[t]{2}{*}{ GmAPX1 } & NM_001250856 & $\mathrm{F}$ & TGGACCTGAAGTTCCATTCCAC \\
\hline & & $\mathrm{R}$ & AAGAAGGCATCTTCGTCCG \\
\hline \multirow[t]{2}{*}{ GmNHX1 } & AY972078 & $\mathrm{F}$ & GGGGCACACTTCACTAAGA \\
\hline & & $\mathrm{R}$ & CCATTACGTTCAGTTGGTGA \\
\hline \multirow[t]{2}{*}{ GmSOS1 } & NM_001258010 & $\mathrm{F}$ & TTACACTACCTTGGCATGGA \\
\hline & & $\mathrm{R}$ & CAGTCACATAGAGGCTCAGA \\
\hline \multirow[t]{2}{*}{ GmCLC1 } & AY972079 & $\mathrm{F}$ & ССАTCATTCTCATGGGTTCC \\
\hline & & $\mathrm{R}$ & ACTTGGATAAGGTGTGCTCT \\
\hline \multirow[t]{2}{*}{ GmActin } & V00450 & $\mathrm{F}$ & GTTCTCTCCTTGTATGCAAGTG \\
\hline & & $\mathrm{R}$ & CCAGACTCATCATATTCACCTTAAG \\
\hline
\end{tabular}

test material and identified and screened PgTIP1 transgenic plants mediated by the pollen tube pathway, and analyzed the physiological and molecular events in enhanced salt tolerance of the representative lines $\mathrm{N}$ and J11. The objective of this study was to systematically reveal the physiological and molecular mechanisms of enhanced salt tolerance of PgTIP1-expressing soybean on aspects of salt stress-caused cell membrane damage, water absorption, salty ion transport, antioxidant enzymes activity or ROS level, and plant growth and photosynthesis, and to provide a theoretical and practical basis for the further exploration of salt-tolerant gene resources to be used in the cultivation or breeding of salt-tolerant transgenic soybean and other crop germplasms.

\section{MATERIALS AND METHODS}

\section{Plant Materials}

Seeds of G. $\max$ (L.) cv. Lee68 were used for PgTIP1 transformation into cotyledon hairy roots and composite plants, cv. Nannong 8831 for PgTIP1-transgenic soybean lines, and subsequent salt tolerance tests.

\section{Construction of the Plant Expression Vector}

Primer sequences designed specifically for amplifying PgTIP1 ORF (753 bp) were: F: CCCAAGCTTATGCCGA TTCACGAAATTGC; R: TCCCCCGGGCTAGTAATCAGCGAC AGGCAA where the underlined nucleotides depict Hind III and Sma I sites. The cDNA from Panax ginseng was used as template for amplification of the PgTIP1 coding region. Amplified PCR products were subcloned into a pMD-18T vector and sequenced (Sangon Biotech., Co. Ltd., China). The ORF of PgTIP1 anchored in the cloning vector was isolated following digestion with Hind III and Sma I and cloned into the plant expression vector (pCAMBIA0390) using a double promoter $(35 \mathrm{~S}+\mathrm{pUbi})$ and NOS terminator.

\section{PgTIP1 Transformation into Soybean Cotyledon Hairy Roots, Composite Plants, and Whole Plants}

The pCAMBIA0390-PgTIP1 was transformed into the K599 strain (A. rhizogenes) for the transformation of soybean (cv. Lee68) cotyledon hairy roots and composite plants, which was conducted as in our previous work (Wei et al., 2016). Additionally, the reconstructed plasmid pCAMBIA0390-PgTIP1 from Escherichia coli DH5 $\alpha$ was transformed into soybean wild type (WT) (cv. Nannong 8831) using the pollen-tube pathway method (Moore et al., 1996; Li and $\mathrm{Wu}, 2007$ ) and advanced to transgenic soybean lines ( $T_{3}$ generation).

\section{Nested PCR Assay}

The nested polymerase chain reaction (PCR) method (Ao et al., 2011) was adopted to detect the exogenous PgTIP1 gene expression in two runs for the transformed soybean cotyledon hairy roots, composite and whole plants, respectively. The 

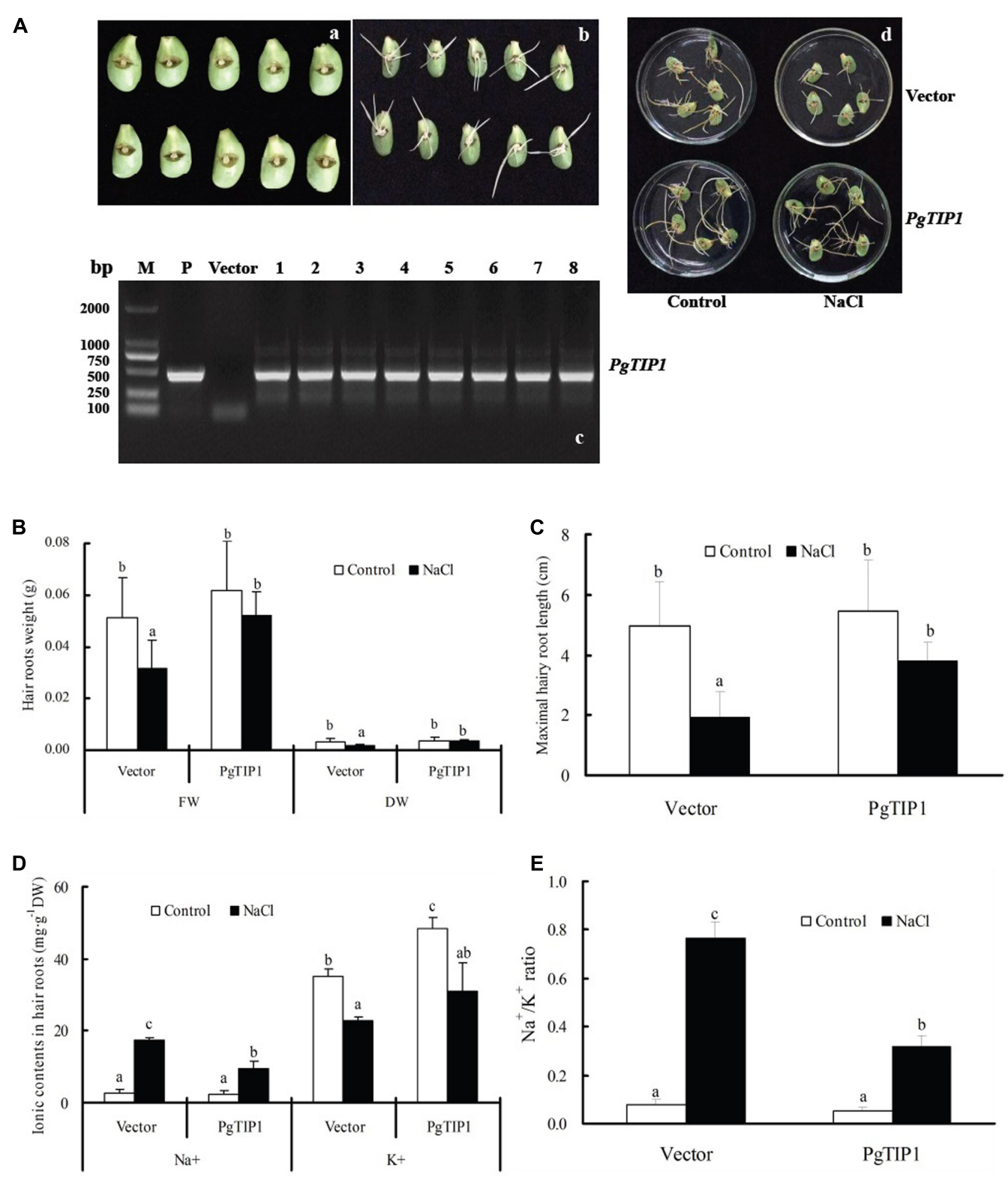

FIGURE 1 | Growth characteristics of hairy roots of PgTIP1-transformed soybean cotyledons under salt stress. (A-a,b) Culture of hairy roots of PgTIP1-transformed soybean cotyledons. (A-c) PCR verification, (A-d) changes in growth phenotype, (B) FW and DW, (C) maximal hairy root length, (D) contents of $\mathrm{Na}^{+}$and $\mathrm{K}^{+}$, and (E) $\mathrm{Na}^{+} / \mathrm{K}^{+}$ratio in the hairy roots under $80 \mathrm{mM} \mathrm{NaCl}$ treatment for 5 days. Each bar represents as means $\pm \mathrm{SD}$ for each treatment $(n=3$; or $n=10$ for fresh weight or maximal length of hairy roots), means in bars followed by different letters show significant difference $(P<0.05)$ between the parameters of the empty vector-transformed and PgTIP1-transfromed soybean cotyledon hairy roots.

primer in the first PCR for a target product of $1,865 \mathrm{bp}$ is as: $\mathrm{F}$ : 5'-CTTCTTCGCCCGCCGTAAT-3', R: 5'-ATGGCTCGTGACT GCTGCTGA- $3^{\prime}$. The primer in the second PCR for a target product of 469 bp is as: F: 5'-TCGGTAGGTACGAAGAG

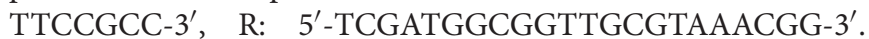
PCR reactions were performed using a PCR-cycler (ABI 2720, Applied Biosystems China, Inc., Beijing), with the reaction mixture consisting of $10 \times$ rTaq buffer $(2.5 \mu \mathrm{L}), 2.5 \mathrm{mM}$ dNTPs $(2 \mu \mathrm{L}), 25 \mathrm{mM} \mathrm{MgCl}_{2}(2 \mu \mathrm{L}), 10 \mu \mathrm{M}$ primer concentration
$(1 \mu \mathrm{L}), 50 \mathrm{ng}$ of prepared cDNA $(1 \mu \mathrm{L}), 5 \mathrm{U} / \mu \mathrm{L}$ rTaq $(0.2 \mu \mathrm{L})$, $16.3 \mu \mathrm{L}$ of $\mathrm{ddH}_{2} \mathrm{O}$ in a final volume of $25 \mu \mathrm{L}$. The first PCR conditions were as follows: an initial denaturation $\left(3 \mathrm{~min}, 94^{\circ} \mathrm{C}\right)$ followed by 35 cycles of denaturation $\left(30 \mathrm{~s}, 94^{\circ} \mathrm{C}\right)$, annealing $\left(50 \mathrm{~s}, 61^{\circ} \mathrm{C}\right)$ and extension $\left(1 \mathrm{~min}\right.$ and $\left.50 \mathrm{~s}, 72^{\circ} \mathrm{C}\right)$, and an additional extension at $72^{\circ} \mathrm{C}$ for $10 \mathrm{~min}$. The second PCR conditions were as follows: an initial denaturation $\left(3 \mathrm{~min}, 94^{\circ} \mathrm{C}\right)$ followed by 35 cycles of denaturation $\left(30 \mathrm{~s}, 94^{\circ} \mathrm{C}\right)$, annealing $\left(30 \mathrm{~s}, 55^{\circ} \mathrm{C}\right)$ and extension $\left(50 \mathrm{~s}, 72^{\circ} \mathrm{C}\right)$, and an additional 


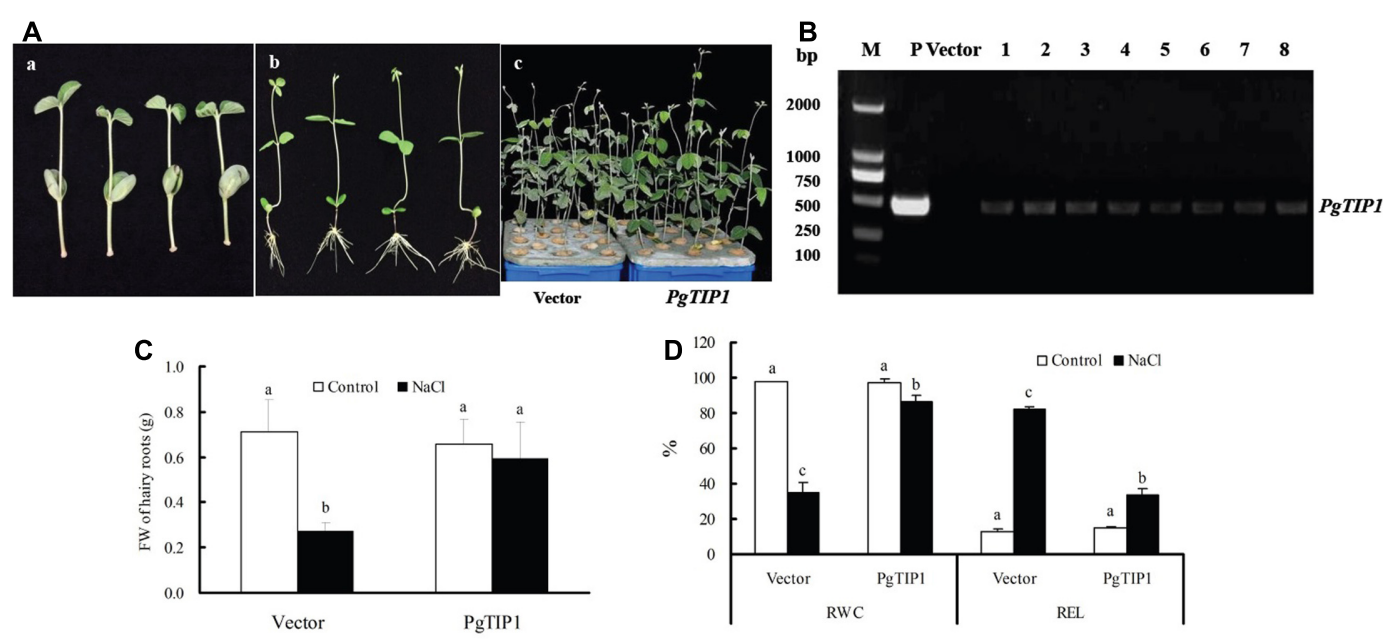

FIGURE 2 | Growth characteristics of PgTIP1-transformed soybean hairy root composite plants under salt stress. (A-a,b) Culture of PgTIP1-transformed soybean hairy root composite plants, (B) PCR verification, (A-c) changes in growth phenotype, (C) FW of hairy roots, and (D) RWC and REL of the 1st pair of unifoliolate leaves under $120 \mathrm{mM} \mathrm{NaCl}$ treatment for 5 days. Each bar represents as means $\pm \mathrm{SD}$ for each treatment $(n=3)$, means in bars followed by different letters show significant difference $(P<0.05)$ between the parameters of the empty vector-transformed and $P g$ TIP1-transfromed soybean hairy root composite plants.

extension at $72^{\circ} \mathrm{C}$ for $10 \mathrm{~min}$. The PCR products were separated on $1.0 \%$ agarose gel and then visualized by Goldview staining on UV transilluminator.

\section{Salt Tolerance Test of PgTIP1-Transformed Soybean Cotyledon Hairy Roots}

The hairy roots of the PgTIP1-transformed soybean cotyledons were obtained according to the methods of Wei et al. (2016) using pCAMBIA0390-PgTIP1-containing A. rhizogenes strain K599. New hairy roots that had sprouted from the infected cotyledons that were free of Agrobacterium, as screened by nested PCR, and at similar lengths were selected and transferred into $1 / 2$ Hoagland solution containing 0 and $80 \mathrm{mM} \mathrm{NaCl}$. Hairy roots infected with $A$. rhizogenes strain K599 containing the empty vector pCAMBIA0390 served as the control. After 5 days of treatment, the root growth was photographed, the maximal root length was quantified with a ruler, and the fresh or dry weights, and extraction and contents of $\mathrm{Na}^{+}$and $\mathrm{K}^{+}$were measured as indicated previously (Wei et al., 2015).

\section{Salt Tolerance Test of PgTIP1-Transformed Soybean Hairy Root Composite Plants}

PgTIP1-transformed soybean (cv. Lee68) hairy root composite plants were obtained according to the methods of Wei et al. (2016) by infection with A. rhizogenes strain K599 containing the pCAMBIA0390-PgTIP1. Hairy roots that were free of Agrobacterium, as screened by nested PCR, were selected and the original roots removed from the seedlings. Seedlings infected with A. rhizogenes strain K599 containing the empty vector pCAMBIA0390 served as the negative control. These seedlings were cultured in $1 / 2$ Hoagland solution for 10 days at $18 \pm 2{ }^{\circ} \mathrm{C}$ to $25 \pm 2{ }^{\circ} \mathrm{C}$ and a $14 \mathrm{~h} / 10 \mathrm{~h}$ (day/night) photoperiod. The seedlings with hairy roots of a similar-length were selected and treated with $1 / 2$ Hoagland solution $(\mathrm{pH}=6.5)$ containing $120 \mathrm{mM} \mathrm{NaCl}$ for 5 days, and seedlings grown in $1 / 2$ Hoagland solution without $\mathrm{NaCl}$ served as the untreated control. During this period, the solutions listed above were replaced once. After 5 days of treatment, the seedlings were photographed, and the fresh weight of the roots, relative water content (RWC), and relative electrolytic leakage (REL) of the 1st pair of unifoliolate leaves, and contents of $\mathrm{Na}^{+}, \mathrm{K}^{+}$of the roots, stems, and whole leaves were measured accordingly. Values of RWC and REL were determined using our previous methods ( $\mathrm{Hu}$ et al., 2016). Extraction and assaying of $\mathrm{Na}^{+}$and $\mathrm{K}^{+}$were also performed as aforementioned.

\section{Salt Tolerance Assay on \\ PgTIP1-Transgenic Soybean Plants}

Seeds ( $\mathrm{T}_{3}$ generation) of PgTIP1 transgenic soybean plants (lines $\mathrm{N}$ and J11) and WT (cv. Nannong 8831) were screened by nested PCR and surface-sterilized with $1 \mathrm{~g} \cdot \mathrm{L}^{-1} \mathrm{HgCl}_{2}$ for $5 \mathrm{~min}$, fully rinsed in distilled water, soaked in distilled water for $10 \mathrm{~h}$, and germinated at $25^{\circ} \mathrm{C}$ in the dark. The germinated seeds (each with $0.5 \sim 1 \mathrm{~cm}$ epicotyl) were planted in plastic pots $(25 \times 18 \mathrm{~cm})$ containing quartz sand, fertigated with $1 / 2$ Hoagland solution, and maintained in a greenhouse with a temperature ranging from $18 \pm 2^{\circ} \mathrm{C}$ to $25 \pm 2{ }^{\circ} \mathrm{C}$ and a $14 \mathrm{~h} / 10 \mathrm{~h}$ (day/night) photoperiod. At the time of the 1st trifoliate leaf expansion, the plants were subjected to salt stress by fertigating with $1 / 2$ Hoagland solution plus $150 \mathrm{mM} \mathrm{NaCl}$, or $1 / 2$ Hoagland solution devoid of $\mathrm{NaCl}$ as the control treatment. The Hoagland solution treatments were replaced every 2 days.

Seven days later, the seedlings were photographed and sampled to measure the RWC of the leaves, REL of the roots and leaves, and $\mathrm{Na}^{+}, \mathrm{K}^{+}$contents in the roots, stems, and leaves 

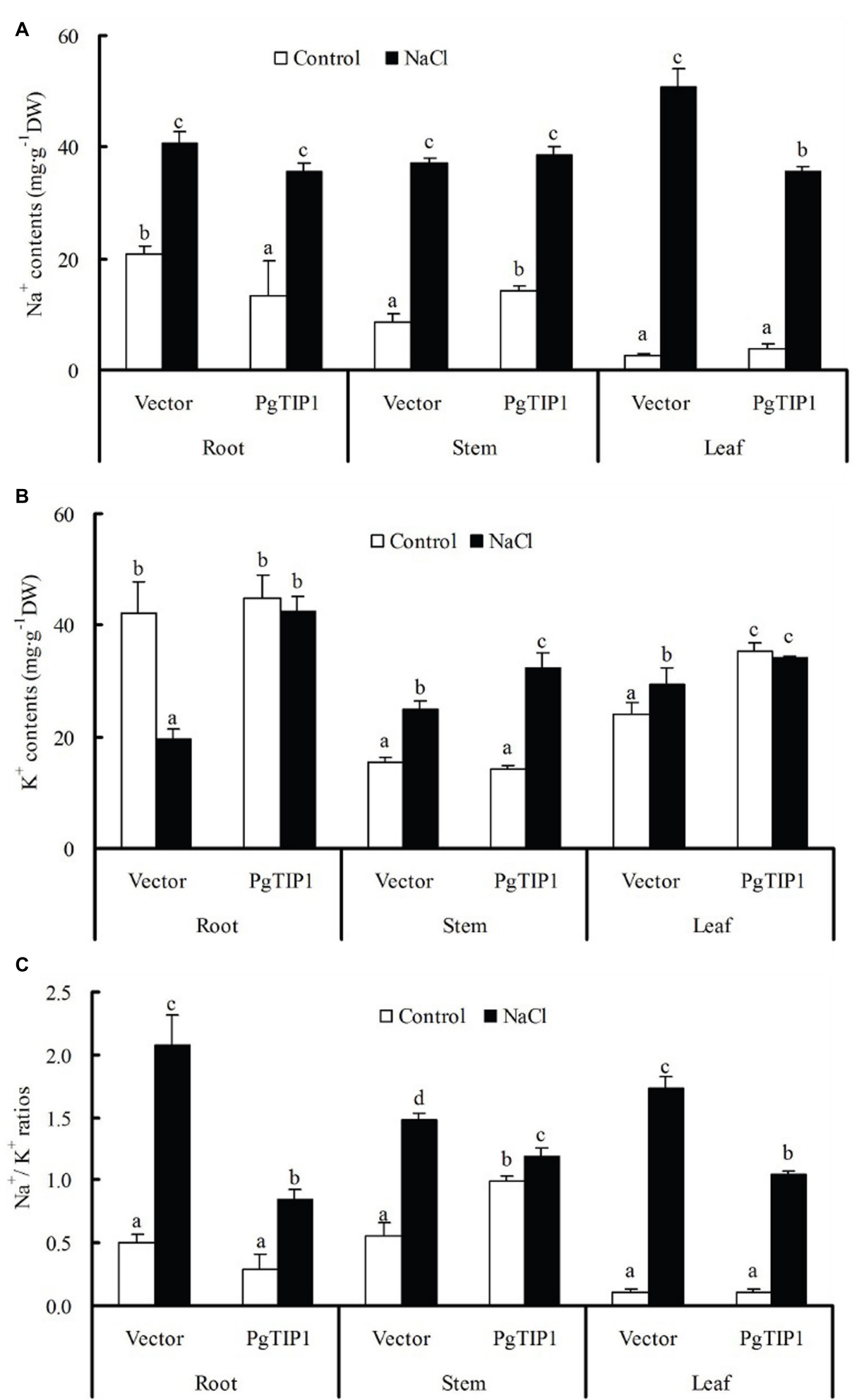

FIGURE 3 | Changes in contents of (A) $\mathrm{Na}^{+}$, (B) $\mathrm{K}^{+}$, and $\mathbf{( C ) ~} \mathrm{Na}^{+} / \mathrm{K}^{+}$ratios in roots, stems and leaves of the empty vector-transformed and PgTIP1-transformed soybean hairy root composite plants under salt stress. The seedlings with hairy roots of a similar-length were selected and treated with $1 / 2$ Hoagland solution containing $120 \mathrm{mM} \mathrm{NaCl}$ for 5 days, and seedlings grown in $1 / 2$ Hoagland solution without $\mathrm{NaCl}$ served as the untreated control. During this period, the solutions listed above were replaced once. The sampled leaves included the 1st pair of unifoliolate, the 1st and 2 nd trifoliate leaves. Each bar represents the mean and SD of three replicates, means in bars followed by different letters show significant difference $(P<0.05)$ between the parameters of the empty vector-transformed and PgTIP1-transfromed soybean hairy root composite plants. 

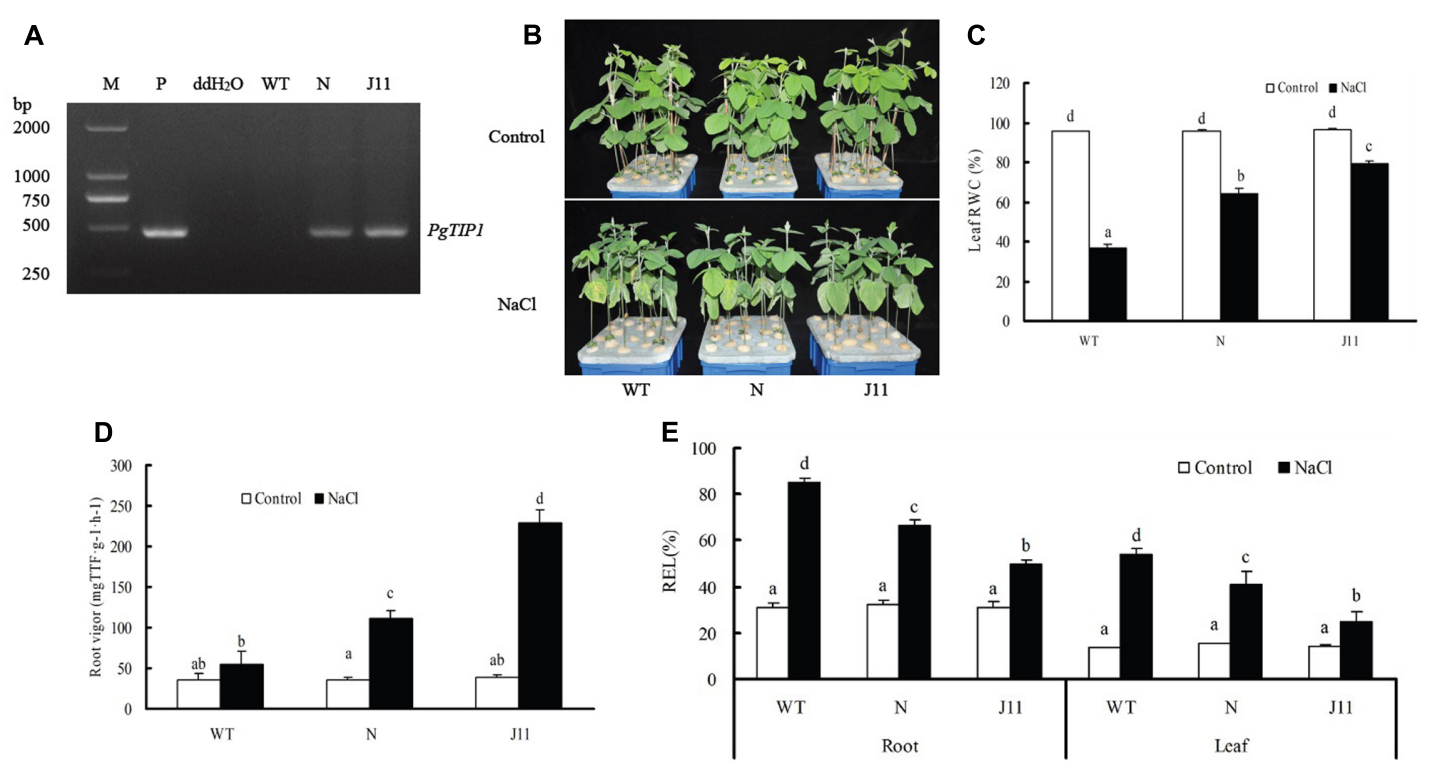

FIGURE 4 | Growth phenotype and physiological responses of WT and PgTIP1-transgenic soybean lines under NaCl treatment. (A) The seedlings ( $T_{3}$ generation) of PgTIP1 transgenic soybean lines N and J11, and WT (cv. Nannong 8831) were screened by PCR. The PCR-verified seeds and WT were surface-sterilized, soaked, germinated, and planted in plastic pots containing quartz sand, fertigated with $1 / 2$ Hoagland solution, and maintained in a greenhouse with a temperature ranging from $18 \pm 2^{\circ} \mathrm{C}$ to $25 \pm 2^{\circ} \mathrm{C}$ and a $14 \mathrm{~h} / 10 \mathrm{~h}$ (day/night) photoperiod. At the time of the 1 st trifoliate leaf expansion, the plants were subjected to salt stress by fertigating with $1 / 2$ Hoagland solution plus $150 \mathrm{mM} \mathrm{NaCl}$, or $1 / 2 \mathrm{Hoagland}$ solution devoid of $\mathrm{NaCl}$ as the control treatment. The Hoagland solution treatments were replaced every 2 days. After 7 days treatment, (B) the growth phenotype was photographed, and measured (C) RWC in the 1st pair of unifoliate leaves, (D) root vigor, and (E) REL in roots and the 1st pair of unifoliate leaves. Each bar represents the mean and SD of three replicates, means in bars followed by different letters show significant difference $(P<0.05)$ between the parameters of WT and PgTIP1-transgenic lines.

using the methods described earlier. Root vigor was determined according to the triphenyltetrazolium chloride (TTC) method (Wang et al., 2012). Chlorophyll and carotenoid contents in the leaves were determined using a UV-9100 spectrophotometer (Beijing, China) following the procedures of Qu et al. (2009). $\mathrm{Cl}^{-}$contents in the roots, stems, and whole leaves were assayed using the method of Zhou and Yu (2009). Net photosynthetic rate $(\mathrm{Pn})$ and transpiration rate $(\mathrm{Tr})$ of the leaves was determined by a portable photosynthesis meter (LI-6400XT, LI-COR Inc., United States). Photosynthetic photon flux density (PPFD), temperature, and $\mathrm{CO}_{2}$ concentration were $1,000 \mu \mathrm{mol} \mathrm{m} \mathrm{m}^{-2} \mathrm{~s}^{-1}$, $28^{\circ} \mathrm{C}$, and $382 \sim 385 \mu \mathrm{mol} \mathrm{mol}{ }^{-1}$, respectively. The maximum photochemical efficiency of PSII $(F \mathrm{v} / F \mathrm{~F})$ was measured at room temperature using a plant efficiency analyzer (Handy PEA Fluorometer, Hansatech Instruments, United Kingdom). The flux density of incident photosynthetically active radiation (PAR) was $3,000 \mu \mathrm{mol} \mathrm{m} \mathrm{m}^{-2} \mathrm{~s}^{-1}$. The leaf blades were dark-adapted for 30 min using Handy-PEA leaf clips and the $F \mathrm{v} / F \mathrm{~m}$ values were read directly (Tian et al., 2014).

The production rate of $\mathrm{O}_{2}^{\bullet-}$ was measured by the modified method of Elstner and Heupel (1976). Briefly, fresh tissues (1.0 g) were homogenized in $2 \mathrm{~mL}$ of $50 \mathrm{mM}$ phosphate buffer ( $\mathrm{pH} 7.8$ ) and then centrifuged at $10,000 \times g$ for $10 \mathrm{~min}$. The supernatants $(1 \mathrm{~mL})$ were mixed with $0.9 \mathrm{~mL}$ of $50 \mathrm{mM}$ phosphate buffer ( $\mathrm{pH} 7.8$ ) and $0.1 \mathrm{~mL}$ of $10 \mathrm{mM}$ hydroxylamine chlorohydrate, and then incubated at $25^{\circ} \mathrm{C}$. After $30 \mathrm{~min}, 1 \mathrm{~mL}$ of the abovementioned culture solution was added to $1 \mathrm{~mL}$ of $17 \mathrm{mM}$ sulfanilamide and $1 \mathrm{~mL} 7 \mathrm{mM} \alpha$-naphthylamine at $25^{\circ} \mathrm{C}$ for $20 \mathrm{~min}$. The absorbance was measured at $530 \mathrm{~nm}$ and $\mathrm{O}_{2}^{\bullet-}$ production rate was calculated from a standard curve of $\mathrm{NaNO}_{2}$. $\mathrm{H}_{2} \mathrm{O}_{2}$ content was measured following the method of Sergiev et al. (1997). Briefly, the roots or leaves $(0.2 \mathrm{~g})$ were homogenized with $2 \mathrm{~mL}$ of $0.1 \%(\mathrm{w} / \mathrm{v})$ trichloroacetic acid (TCA) in an ice bath and then centrifuged at $12,000 \times g$ for $15 \mathrm{~min}$ at $4^{\circ} \mathrm{C}$. Then, $0.5 \mathrm{~mL}$ of the supernatant was added to $0.5 \mathrm{~mL} 10 \mathrm{mM}$ phosphate buffer ( $\mathrm{pH} 7.0)$ and $1 \mathrm{~mL} 1 \mathrm{M} \mathrm{KI}$. The absorbance of the mixture was read at $390 \mathrm{~nm}$. Finally, the content of $\mathrm{H}_{2} \mathrm{O}_{2}$ was calculated from a standard curve. The antioxidant enzyme extractions were performed according to the method of our previous work (Zhao et al., 2017), the roots or leaves $(0.2 \mathrm{~g}$ ) were homogenized in a mortar and pestle with $2 \mathrm{~mL}$ of $50 \mathrm{mM}$ ice-cold phosphate buffer ( $\mathrm{pH} 7.0$ ) containing $1 \mathrm{mM}$ EDTA $\cdot \mathrm{Na}_{2}$ and $0.5 \%$ PVP $(w / v)$. The homogenate was centrifuged at $15,000 \times g$ for $15 \mathrm{~min}$ at $4^{\circ} \mathrm{C}$. The supernatant was used as the enzyme extract for assays of SOD, POD, CAT, and APX activities. SOD activity was assayed using the photochemical nitroblue tetrazolium (NBT) method (Beauchamp and Fridovich, 1971). The reaction mixture contained $100 \mathrm{mM}$ phosphate buffer ( $\mathrm{pH} 7.8$ ), $130 \mathrm{mM}$ methionine, $750 \mu \mathrm{M}$ NBT, $20 \mu \mathrm{M}$ riboflavin, $1 \mathrm{mM}$ EDTA $\cdot \mathrm{Na}_{2}$, deionized water, and $80 \mu \mathrm{L}$ enzyme extracts in a $3 \mathrm{~mL}$ volume. One unit of SOD activity was defined as the amount of enzyme required to cause $50 \%$ inhibition of NBT reduction monitored at $560 \mathrm{~nm}$. POD activity was measured with guaiacol as the substrate according to Nakano and Asada (1981). The reaction 

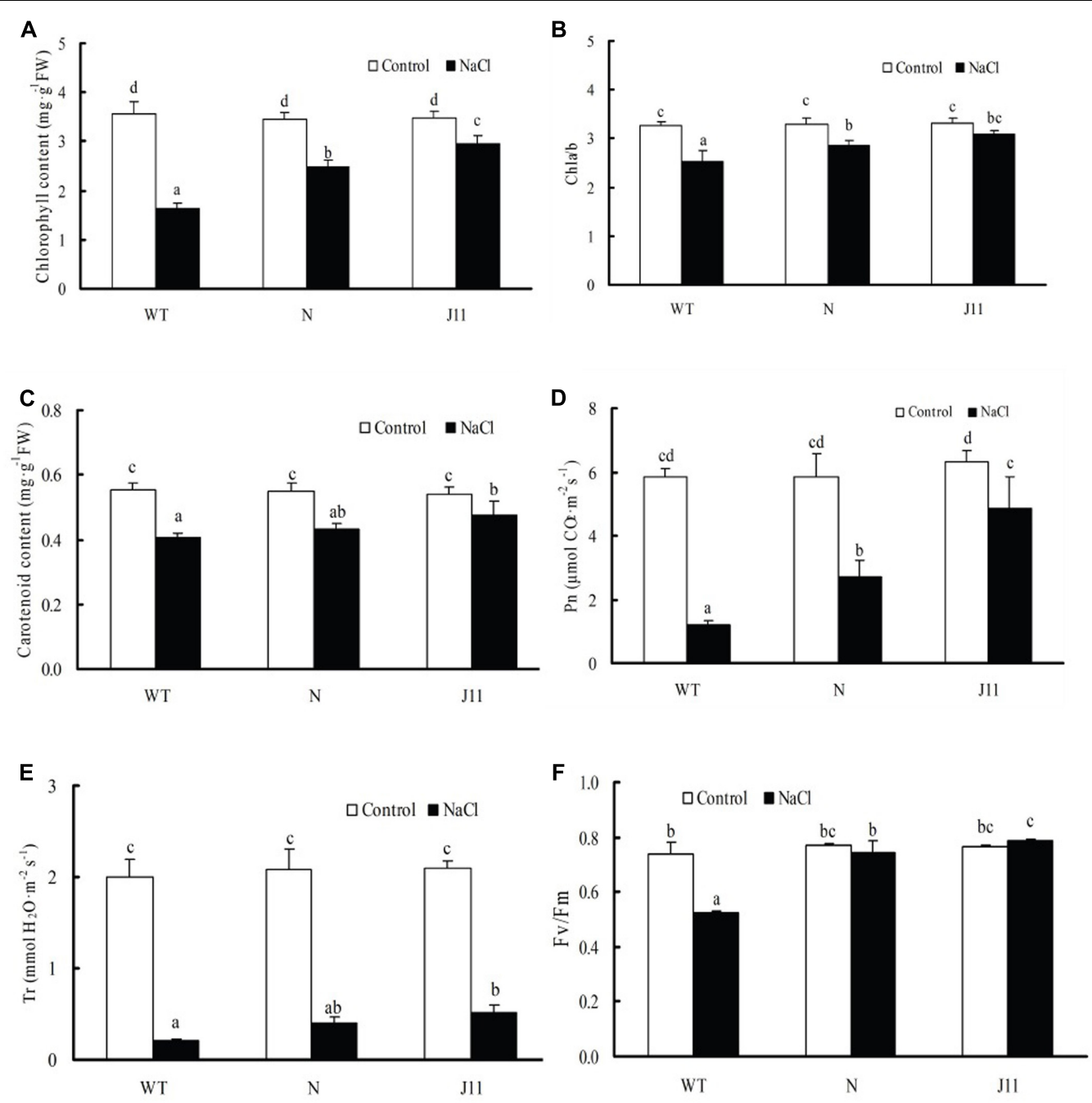

FIGURE 5 | Changes in photosynthetic parameters in leaves of WT and PgTIP1-transgenic soybean lines under NaCl treatment. The plants of WT and PgTIP1 transgenic soybean lines $\mathrm{N}$ and $\mathrm{J} 11$ were cultured and $\mathrm{NaCl}$-treated as above-mentioned in Figure $\mathbf{4}$. After 7 days treatment, the 1 st pair of unifoliate leaves were sampled for measuring (A) chlorophyll content, (B) chla/b, (C) carotenoids content, or used for measuring (D) Pn, (E) Tr, and (F) Fv/Fm in leaves of WT and PgTIP1-transgenic soybean lines. Each bar represents the mean and SD of three replicates, means in bars followed by different letters show significant difference $(P<0.05)$ between the parameters of WT and PgTIP1-transgenic lines.

mixture $(3 \mathrm{~mL})$ consisted of $100 \mathrm{mM}$ sodium acetate buffer

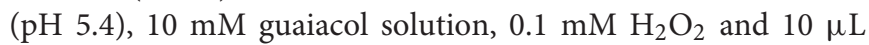
enzyme extracts. The increase in absorbance due to oxidation of guaiacol was measured at $470 \mathrm{~nm}$ for $1 \mathrm{~min}$. One unit of POD activity was defined as a change in absorbance of 0.1 unit $\cdot \mathrm{min}^{-1}$. CAT activity was assayed according to Aebi (1984). The 3-mL reaction mixture contained $0.1 \mathrm{~mL}$ of enzyme extracts, $0.1 \mathrm{M}$ phosphate buffer ( $\mathrm{pH} 7.0$ ), deionized water and $20 \mathrm{mM} \mathrm{H} \mathrm{O}_{2}$. The decomposition of $\mathrm{H}_{2} \mathrm{O}_{2}$ was measured by following the decrease in absorbance at $240 \mathrm{~nm}$ for $3 \mathrm{~min}$ and quantified by its molar extinction coefficient $\left(39.4 \mathrm{mmol} \cdot \mathrm{L}^{-1} \cdot \mathrm{cm}^{-1}\right)$. One unit of CAT activity was defined as a change in absorbance of 0.1 units $\min ^{-1}$ caused by addition of the enzyme extracts. APX activity was assayed following the method of Nakano and Asada (1981). The reaction mixture of $3 \mathrm{~mL}$ contained $100 \mathrm{mM}$ phosphate
(pH 7.0), $100 \mathrm{mM}$ ascorbic acid, $0.1 \mathrm{mM} \mathrm{H}_{2} \mathrm{O}_{2}$, deionized water and $0.1 \mathrm{~mL}$ enzyme extracts. The reaction was started by adding enzyme extracts to the mixture. Enzyme activity was quantified by following the decrease in absorbance at $290 \mathrm{~nm}$ for $3 \mathrm{~min}$. One unit of APX activity was defined as an absorbance change of 0.01 units $\cdot \min ^{-1}$.

For semi-quantitative RT-PCR analysis of the stress-related genes expression, total RNA was isolated from the roots and leaves of soybean cv. Nannong 8831 and PgTIP1-transgenic lines $\mathrm{N}$ and $\mathrm{J11}$ using a MiniBEST Plant RNA Extraction Kit (TaKaRa) according the manufacturer's instructions. The RNA was stored at $-80^{\circ} \mathrm{C}$ and total RNA was quantified using a NanoDrop spectrophotometer. First-strand cDNAs were synthesized from total RNA using a PrimeScript RT reagent kit (TaKaRa). Semiquantitative RT-PCR was performed at least three independent 

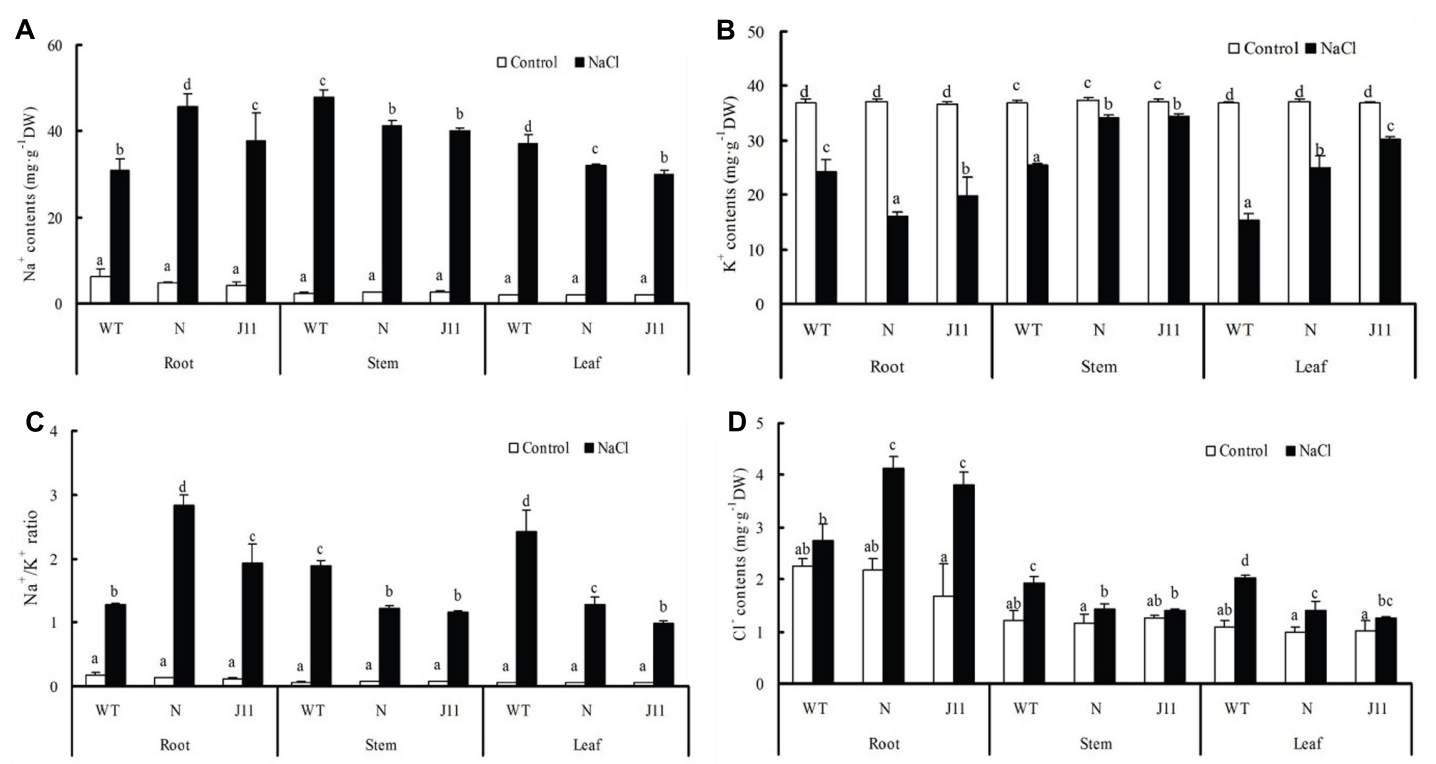

FIGURE 6 | Changes in ion contents of plants of PgTIP1-transgenic soybean lines and WT under NaCl treatment. The plants of WT and PgTIP1 transgenic soybean lines $\mathrm{N}$ and $\mathrm{J} 11$ were cultured and $\mathrm{NaCl}$-treated as above-mentioned in Figure 4. After 7 days treatment, the roots, stems and leaves (including the 1st pair of unifoliolate, the 1st and 2nd trifoliate leaves) were sampled for measuring contents of (A) $\mathrm{Na}^{+}$and (B) $\mathrm{K}^{+},(\mathbf{C}) \mathrm{Na}^{+} / \mathrm{K}^{+}$ratios, and (D) $\mathrm{Cl}^{-}$content. Each bar represents the mean and SD of three replicates, means in bars followed by different letters show significant difference $(P<0.05)$ between the parameters of $\mathrm{WT}$ and PgTIP1-transgenic lines.

replicates using a pair of gene-specific primers. The housekeeping gene GmActin was used as an internal control. The amplification program for this work was performed at $94^{\circ} \mathrm{C}$ for $5 \mathrm{~min}$, followed by 28 cycles of $94^{\circ} \mathrm{C}$ for $30 \mathrm{~s}, 53^{\circ} \mathrm{C}$ for $30 \mathrm{~s}, 72^{\circ} \mathrm{C}$ for $50 \mathrm{~s}$, and a final extension of $72^{\circ} \mathrm{C}$ for $10 \mathrm{~min}$. All primers used for RT-PCR are listed in Table 1. Note: in all experiments for PgTIP1transgenic soybean lines, the 1st pair of unifoliolate leaves were used for the assays, with the exception of measurements of leaf $\mathrm{Na}^{+}, \mathrm{K}^{+}$, and $\mathrm{Cl}^{-}$contents using whole leaves (including the 1st pair of unifoliolate, the 1st and 2nd trifoliate leaves).

\section{Statistical Analyses}

All data were analyzed and presented as means \pm SD for each treatment ( $n=3$; or $n=10$ for fresh weight or maximal length of hairy roots) using SPSS software ver. 20.0, and the mean differences were assessed using Duncan's test $(P<0.05)$.

\section{RESULTS}

\section{PgTIP1 Mitigates NaCl Stress on Transformed Soybean Cotyledon Hairy Roots by Reducing $\mathrm{Na}^{+}$Accumulation and $\mathrm{Na}^{+} / \mathrm{K}^{+}$Ratio}

Using the A. tumefaciens K599-mediated hairy roots system, the empty vector-transformed and PgTIP1-transformed soybean (cv. Lee68) cotyledon hairy roots were obtained and the positive lines were identified by nested PCR (Figures 1A-a,b,c). When the empty vector-transformed and PgTIP1-transformed soybean cotyledon hairy roots were exposed to $80 \mathrm{mM} \mathrm{NaCl}$ solution for 5 days, root growth was clearly inhibited in comparison with the non-treated ones, especially the empty vector-transformed cotyledon hair roots (Figure 1A-d). This phenomenon is also reflected in the decreasing fresh or dry root weight (Figure 1B) and maximal root length (Figure 1C) extents under salt treatment. With respect to $\mathrm{Na}^{+}$and $\mathrm{K}^{+}$contents, salt stress significantly increased $\mathrm{Na}^{+}$content and reduced $\mathrm{K}^{+}$content, accordingly resulting in a large rise in the $\mathrm{Na}^{+} / \mathrm{K}^{+}$ratio in the empty vector-transformed and PgTIP1-transformed soybean cotyledon hairy roots. Notably, the increasing ranges of $\mathrm{Na}^{+}$ content and $\mathrm{Na}^{+} / \mathrm{K}^{+}$ratio in the empty vector-transformed soybean cotyledon hairy roots were remarkably higher than those of the PgTIP1-transformed (Figures 1D,E).

\section{PgTIP1 Alleviates Salt Injury on Transformed Soybean Hairy Root Composite Plants by Adjusting Water Relations, $\mathrm{Na}^{+}$and $\mathrm{K}^{+}$Levels}

When the 1st pair of unifoliolate leaves had fully expanded, the normally cultivated soybean (cv. Lee68) seedlings were pruned from the original roots and infected by immersing the cotyledon hypocotyls with empty vector-contained and PgTIP1-contained A. tumefaciens K599. After approximately 20 days of culture, soybean hairy root composite plants were eventually formed (Figures $\mathbf{2 A - a}, \mathbf{b}$ ). Then, 8 to 10 seedlings were randomly selected for PgTIP1-transformation verification by nested PCR, and fine transformation efficiency was displayed 
(Figure 2B). When the empty vector-transformed and PgTIP1transformed soybean hairy root composite plants were treated with $120 \mathrm{mM} \mathrm{NaCl}$ for 5 days, the leaves of the former showed obvious wilting, while the transgenic plants suffered much less (Figure 2A-c). The fresh weights (FW) of the hairy roots and the RWCs of the unifoliolate leaves of the empty vectortransformed plants were significantly decreased in comparison to the untreated plants, but the REL of unifoliolate leaves increased significantly $(P<0.05)$. The overall changes in PgTIP1transformed composite plants were relatively smaller, and the decrease in FW of the hairy roots was not statistically significant $(P>0.05$; Figures 2C,D).

Under salt stress, the $\mathrm{Na}^{+}$contents in the roots, stems, and leaves of empty vector-transformed and PgTIP1-transformed hairy root composite plants were significantly higher than those of untreated plants $(P<0.05)$. The increases in $\mathrm{Na}^{+}$content in the roots and stems of the two types of soybean plants were similar, but the rise in $\mathrm{Na}^{+}$content in the leaves of the PgTIP1-transformed composite plants was markedly lower than that of the empty vector-transformed plants (Figure 3A). As for $\mathrm{K}^{+}$contents, the $\mathrm{NaCl}$ treatment led to a significant drop or slight decline in the roots of empty vector-transformed or PgTIP1-transformed composite plants, respectively, but $\mathrm{K}^{+}$ contents in the stems and leaves of both soybean plants showed an increasing trend, and those of PgTIP1-transformed plants were evidently higher than the empty vector-transformed plants (Figure 3B). Echoed by the changes in $\mathrm{K}^{+}$and $\mathrm{Na}^{+}$contents, the $\mathrm{Na}^{+} / \mathrm{K}^{+}$ratios in the roots, stems, and leaves of both soybean plants were significantly increased under salt stress, and as a whole, the increases in PgTIP1-transformed plants were obviously lower than the empty vector-transformed plants (Figure 3C).

\section{PgTIP1 Alleviates NaCl Stress on Transgenic Soybean Plants by Reducing Cell Membrane Damage, Improving Photosynthesis and Antioxidant Enzyme Activities, and Adjusting Ionic Distribution}

At the whole plant level, two PgTIP1-transgenic soybean lines $\mathrm{N}$ and J11 (cv. Nannong 8831 as WT) were identified by nested PCR (Figure 4A). Under favorable conditions, seedlings of WT and transgenic soybean lines all grew well. When subjected to $150 \mathrm{mM} \mathrm{NaCl}$ solution for 7 days, WT plants displayed obvious withering and yellowing of the leaves and lower RWC in the leaves, whereas the two PgTIP1-transgenic lines showed relatively mild salt injury symptoms and maintained relatively higher leaf RWC. The J11 line particularly appeared healthier (Figures 4B,C). Under salt stress, root vigor of WT and two transgenic lines were all enhanced with the exception of the $\mathrm{NaCl}$ treated and untreated WT plants which showed no significant difference $(P>0.05)$. With regards to both transgenic-PgTIP1 lines, J11 showed the highest root vigor in the NaCl-treatment (Figure 4D). When taking into consideration the REL values of salt-stressed roots and leaves, remarkable increases were observed in the three types of soybean material in comparison with each control, and the increases in lines $\mathrm{N}$ and J11 were visibly lower that WT, and J11 presented the smallest change (Figure 4E).

Under $150 \mathrm{mM} \mathrm{NaCl}$ treatment for 7 days, the chlorophyll and carotenoid contents, chla/b ratios, and values of $\mathrm{Pn}$ and $\mathrm{Tr}$ in the leaves of WT and PgTIP1-transgenic lines N and J11 were all inferior to those of each control. Drops in these parameters in WT approached the significant level $(P<0.05)$, while declines in both the transgenic lines were relatively smaller. In particular, declines in the chla/b ratio of J11 showed no significant difference to untreated plants $(P>0.05)$, and its Tr value was even significantly higher than that of salt-stressed WT plants (Figures 5A-E). With respect to the maximum photochemical efficiency of PSII $\left(F_{\mathrm{V}} / F_{\mathrm{m}}\right)$, it was evidently depressed $(P<0.05)$ in salt-stressed WT, but no significant changes in the transgenic lines $\mathrm{N}$ and the J11 were observed, and J11 even exhibited a slight increase $(P>0.05)$ (Figure 5F).

Under salt stress, $\mathrm{Na}^{+}$and $\mathrm{Cl}^{-}$contents in the roots, stems, and leaves of WT and the transgenic lines $\mathrm{N}$ and J11 were obviously increased compared to each of the non-treated plants, and variations in $\mathrm{Na}^{+}$level were particularly large. Conversely, the $\mathrm{K}^{+}$contents in the roots, stems, and leaves of the three types of soybean seedlings were distinctly decreased, therefore leading to sharp increases in the $\mathrm{Na}^{+} / \mathrm{K}^{+}$ratio. Interestingly, increases in the ranges of $\mathrm{Na}^{+}$and $\mathrm{Cl}^{-}$contents and $\mathrm{Na}^{+} / \mathrm{K}^{+}$ratio, together with the lower ranges of $\mathrm{K}^{+}$contents in the roots of $\mathrm{NaCl}$-treated transgenic lines $\mathrm{N}$ and $\mathrm{J1} 1$ were clearly greater than those in the roots of WT, but the opposite was observed for the shoots including the stems and leaves, and in particular, $\mathrm{Cl}^{-}$content in the stems of transgenic line J11 did not differ significantly to the control (Figure 6).

Under $\mathrm{NaCl}$ treatment for 7 days, $\mathrm{H}_{2} \mathrm{O}_{2}$ content and $\mathrm{O}_{2}^{\bullet-}$ production rate in the roots and leaves of WT were significantly increased compared with the control, while for transgenic lines $\mathrm{N}$ and $\mathrm{J11}$ the $\mathrm{H}_{2} \mathrm{O}_{2}$ content in the roots and leaves, and $\mathrm{O}_{2}^{\bullet-}$ production rate in the leaves, were obviously decreased in contrast with each control (Figures 7A,B), with the exception of the obvious rise in $\mathrm{O}_{2}^{\bullet-}$ production rate in the roots (but lower than in WT). Salt exposure resulted in enhanced SOD and POD activity in the roots and leaves of the three types of soybean plants, and the enhancing effects on transgenic lines $\mathrm{N}$ and J11, especially the latter, were pronounced (Figures 7C,D). Additionally, CAT activities in the roots of $\mathrm{N}$ and $\mathrm{J} 11$ were improved by salt stress in comparison to the control, whereas CAT activity in the roots and leaves of WT and the leaves of N and J11, and APX activity in the leaves of the three types of soybean decreased significantly, and WT showed the largest drop (Figures 7E,F).

\section{Transcriptional Patterns of Stress-Related Genes in the Roots and Leaves of $\mathrm{NaCl}$-Treated PgTIP-Transgenic Soybean Plants}

Considering soybean endogenous stress-related genes as the pointcut, when seedlings of PgTIP1-transgenic lines $\mathrm{N}$ and J11, and WT, were exposed to $150 \mathrm{mM} \mathrm{NaCl}$ for $24 \mathrm{~h}$, the 

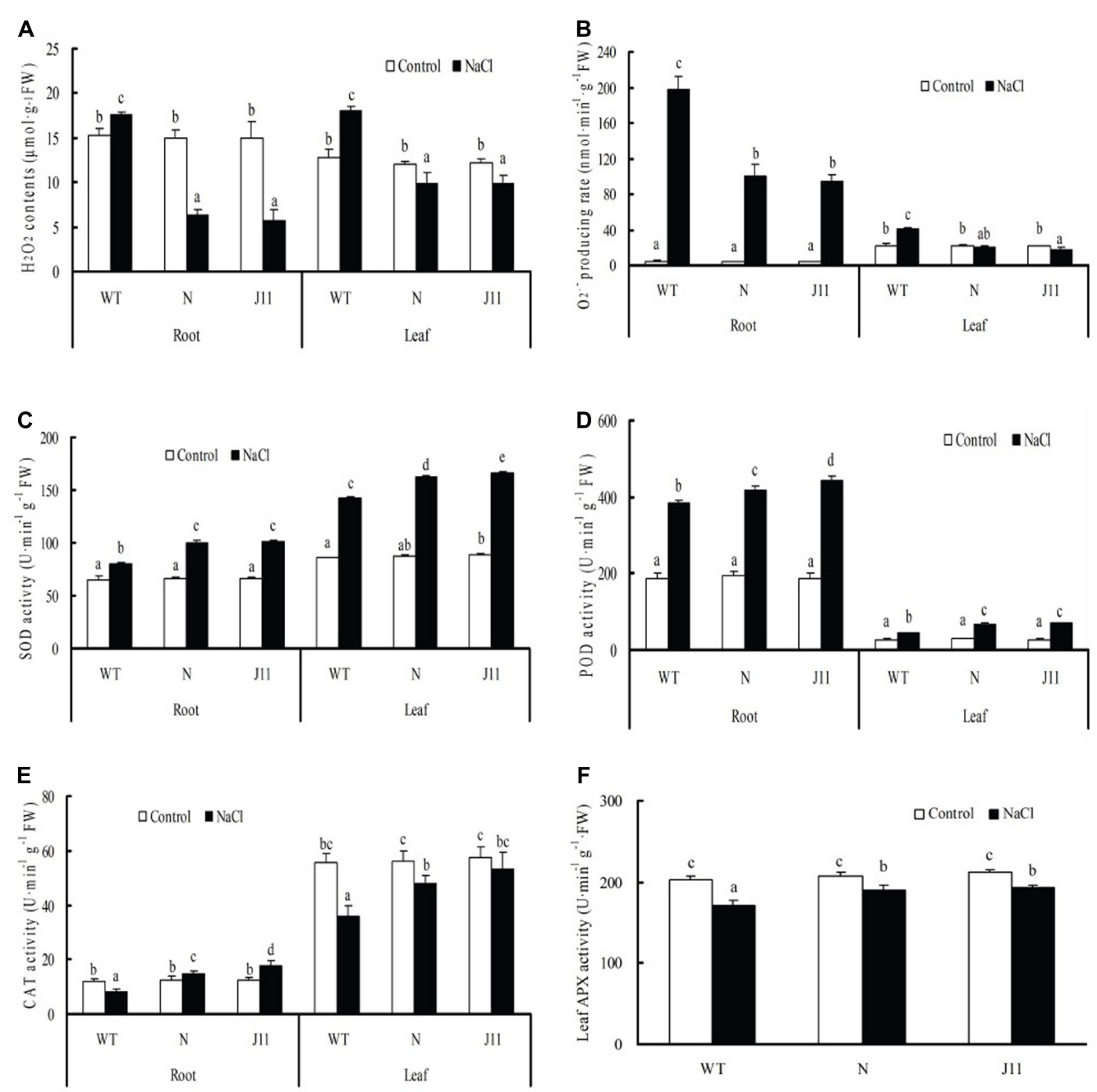

FIGURE 7 | Changes in ROS levels and antioxidant enzyme activities of plants of PgTIP1-transgenic soybean lines and WT under NaCl treatment. The plants of WT and PgTIP1 transgenic soybean lines $\mathrm{N}$ and $\mathrm{J} 11$ were cultured and $\mathrm{NaCl}$-treated as above-mentioned in Figure 4 . After $7 \mathrm{~d}$ treatment, the roots and the 1st pair of unifoliolate leaves were sampled for measuring (A) $\mathrm{H}_{2} \mathrm{O}_{2}$ content, (B) $\mathrm{O}_{2}^{\bullet-}$ producing rate, activities of (C) SOD, (D) POD, (E) CAT, and (F) APX. Each bar represents the mean and SD of three replicates, means in bars followed by different letters show significant difference $(P<0.05)$ between the parameters of WT and PgTIP1-transgenic lines.

transcriptional levels of $G m P O D$ and $G m A P X 1$, which partly contribute toward the maintenance of cellular ROS homeostasis, were obviously heightened in the roots and leaves of the two transgenic lines compared to WT. The expression levels of GmSOD1 and GmCAT1 in the roots and leaves displayed unobvious variation among the three. The expression of GmSOS1 and $G m C L C 1$, which are directly involved in cellular $\mathrm{Na}^{+}$and $\mathrm{Cl}^{-}$homeostasis, were also reinforced in the roots and leaves of $\mathrm{N}$ and J11, although the transcription of the GmNHX1 gene, which is important for intracellular $\mathrm{Na}^{+}$compartmentation, showed no difference in the roots and leaves under favorable or saline conditions. We also investigated two representative soybean TIP genes, GmTIP1;1 and GmTIP1;3 for the highest homology of $P g T I P 1$, and found that both expressions were scarcely affected in the roots and were similarly enhanced in the leaves under salt treatment (Figures 8A,B).

\section{DISCUSSION}

Water deficit commonly damages plants suffering under various adverse conditions, and salt stress, ionic poison, nutritional imbalance, and ROS injury often also occur under such circumstances. The maintenance of water status is not only vital for the growth of plants under favorable conditions, but is also crucial for plant adaptation to salt, drought, and other abiotic stresses (Hu et al., 2016). Plant water relations and ionic homeostasis with reciprocal regulation are important key factors that contribute toward salt tolerance in plants. Plant AQPs play a crucial role in maintaining plant water homeostasis under normal or stressful environments, and among of them, PIPs, as the largest category, are located in the plasma membrane (PM) and generally control both water uptake through the roots and water loss via the leaves by the symplastic route 

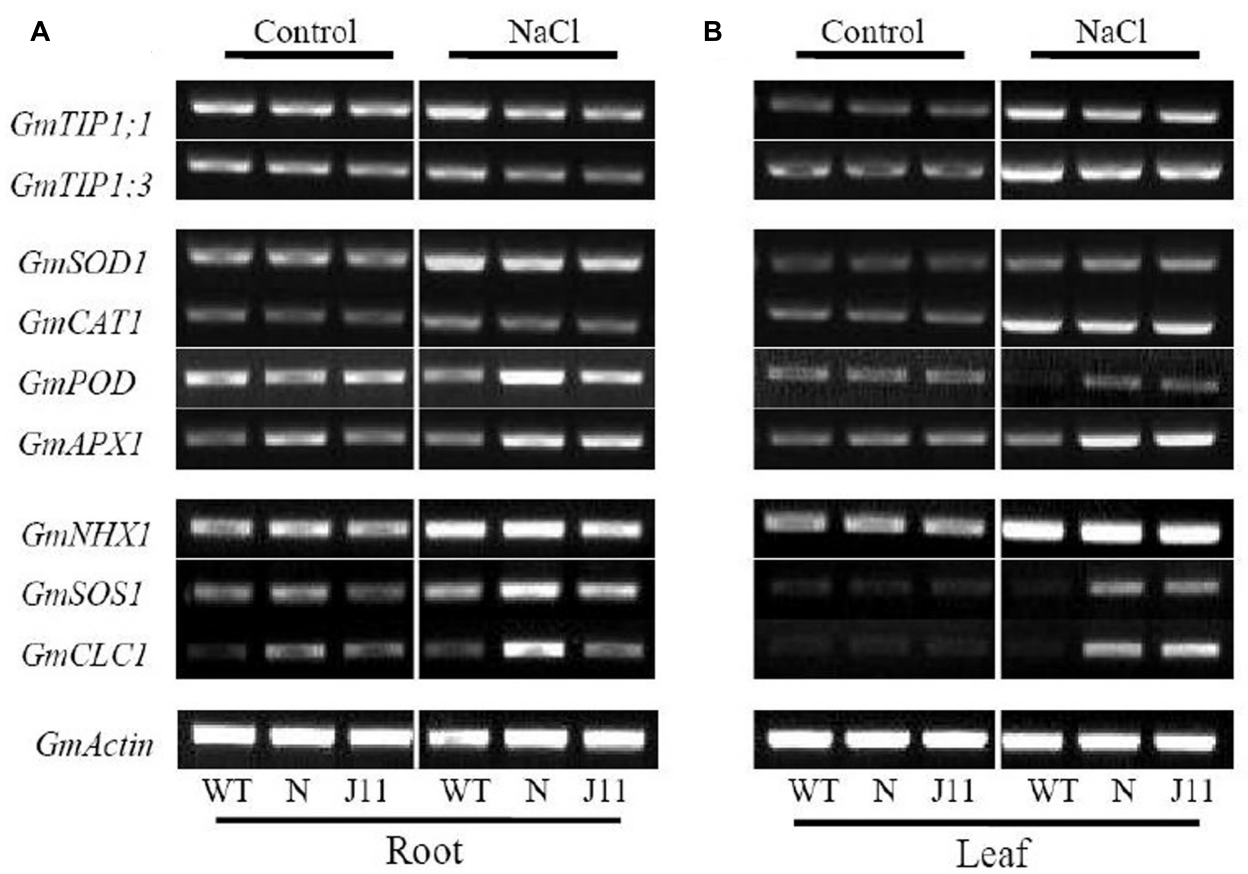

FIGURE 8 | Transcriptional patterns of stress-related genes in plants of NaCl-treated WT and PgTIP-transgenic soybean lines. At the time of the 1st trifoliate leaf expansion, plants of PgTIP1-transgenic soybean lines N and J11, and WT were subjected to $150 \mathrm{mM} \mathrm{NaCl}$ treatment for $24 \mathrm{~h}$, the genes expression patterns of GmSOD1, GmCAT1, GmPOD, GmAPX1, GmNHX1, GmSOS1, GmCLC1, GmTIP1;1, and GmTIP1:3 in (A) roots and (B) leaves were analyzed by semi-quantitative RT-PCR using a pair of gene-specific primers (listed in Table 1), which was performed at least three independent replicates, and the representative one was showed. The housekeeping gene GmActin was used as an internal control.

through cytoplasmic continuities and plasmodesmata, and the transcellular path across cell plasma membranes (Maurel et al., 2008). At present, homologous overexpression or heterologous expression of one or more particular AQP gene has become a widely used strategy to uncover its functions in plant water relations or homeostasis under water deficit caused by salt or drought stress, and possibly presents a feasible approach for the development of transgenic crop cultivars with improved tolerance to abiotic and biotic stresses. The antisense NtAQP1expressing tobacco plants showed more sensitivity to drought stress (Siefritz et al., 2002), and the over-expression of NtAQP1 in tobacco plants displayed enhanced salt stress resistance in comparison with wild plants (Sade et al., 2010). Rice OsPIP1;1 or OsPIP2;2-transgenic Arabidopsis plants showed enhanced tolerance to salt and drought stress (Guo et al., 2006). Conversely, the overexpression of VvPIP2;4N in grapevine plants resulted in good growth under favorable water conditions, but more severe damage than the control plants under drought stress (Perrone et al., 2012). Overexpression of a barley AQP HvPIP2;1, the expression of which was down-regulated under salt stress, could increase salt sensitivity in transgenic rice plants (Katsuhara et al., 2003). Our previous study on ectopic soybean overexpression of VzPIP2;1 from droughttolerant vetiver grass suggested that gene expression mediated by A. tumefaciens transformation at the whole plant level decreased the drought resistance of transgenic soybean plants, while the composite soybean plants with transgenic hairy roots mediated by $A$. rhizogenes showed enhanced drought tolerance (Hu et al., 2016). Thus, the response of plant PIPs to abiotic stresses such as salinity, drought, and cold are complex, and homologously overexpressed or heterologously expressed PIPs may either beneficially or adversely effect stress tolerance depending on the investigated AQP genes, organs, or plant species or stress factors (Maurel et al., 2008).

Tonoplast intrinsic proteins, as a major and plant-specific subfamily of AQPs, can regulate water exchange between the cytoplasm and vacuole and control cell water homeostasis involved in cellular storage, osmotic adjustment and turgor control, cell signaling and digestion, and abiotic stress tolerance (Peng et al., 2007; Wang et al., 2011; Xin et al., 2014; Song et al., 2016). Therefore, plants or crops may be conferred with increased tolerance toward different abiotic stresses through a suitable TIP-transgenic approach (Srivastava et al., 2014). For example, ectopic overexpression of TsTIP1;2 from the halophyte Thellungiella salsuginea in Arabidopsis notably increased tolerance for drought, salt, and oxidative stresses (Wang et al., 2014). Transgenic Arabidopsis plants expressing SITIP2;2 from Solanum lycopersicum exhibited enhanced salt stress tolerance by regulating ion (including $\mathrm{Na}^{+}$and $\mathrm{K}^{+}$) homeostasis and antioxidant enzyme activities under salt treatment (Xin et al., 2014). A high water channel activity was displayed by PgTIP1-heterologous expression in Xenopus laevis oocytes and in yeast, and a significant role in growth and development under favorable conditions and enhanced salt 
and drought tolerance, together with upregulated expression of the stress-related genes, was demonstrated in PgTIP1-transgenic Arabidopsis plants (Lin et al., 2007; Peng et al., 2007; Li and Cai, 2015). In our work, we successfully obtained PgTIP1transformed soybean cotyledon hairy roots and composite plants mediated by A. rhizogenes, and PgTIP1-transgenic plants (lines $\mathrm{N}$ and J11) through the pollen tube pathway without a marker gene (Figures 1A, 2A, 4B). However, as a technical problem occurred as a result of the large and complex soybean genome and sharing of exogenous PgTIP1 with high homology of soybean GmTIPs family itself, we thus adopted nested PCR (with $0.005 \%$ sensitivity) instead of standard PCR (with $0.5 \%$ sensitivity; Ao et al., 2011) for positive identification of PgTIP1transformed soybean materials, and showed fine effectiveness (Figures 1A-c, 2B, 4A).

Under salt stress, and compared to empty vector-transformed cotyledon hairy roots or composite plants, the PgTIP1transformed cotyledon hairy roots or composite plants suffered far lighter salt injury symptoms, and this could be well reflected from the biomass reduction (fresh and dry weight, or maximal length of hairy roots) (Figures 1B,C, 2C) or withering degree (Figure 2A-c), leaf RWC drop and REL rise (Figure 2D) of composite plants. Of course, more important explanations for the differences in salt injury between PgTIP1-transformed and empty vector-transformed cotyledon hairy roots or composite plants exist in that $\mathrm{Na}^{+}$contents in PgTIP1-transformed cotyledon hairy roots or roots, stems, and leaves of PgTIP1-transformed composite plants lowered significantly under salt stress in comparison with the empty vector-transformed, while $\mathrm{K}^{+}$levels were relatively better maintained at the same time, eventually leading to notably lower $\mathrm{Na}^{+} / \mathrm{K}^{+}$ratios than the empty vectortransformed (Figures 1D,E, 3A-C). This is the first study on the aspect of root-specificity and heterologous overexpression of PgTIP1 that demonstrated that water relations and ion homeostasis of PgTIP1-transformed soybean cotyledon hairy roots or composite plants are well adjusted under salt stress, and thus confer enhanced salt tolerance. On this basis, our further investigation using PgTIP1-transgenic soybean lines (N and J11) showed that at the whole plant level, apart from a similar ability to adjust water relations (Figure 4C) as well as less salt damage (expressed as a REL) (Figure 4E) as the above-mentioned soybean hairy roots test, plant root vigor (Figure 4D) and a series of photosynthesis and fluorescence parameters, including leaf chlorophyll and carotenoid contents, chla/b ratio, and $\mathrm{Pn}, \mathrm{Tr}$, and Fv/Fm values (Figure 5), were well maintained under salt stress in comparison to WT. With regards to $\mathrm{Na}^{+}$and $\mathrm{K}^{+}$contents and $\mathrm{Na}^{+} / \mathrm{K}^{+}$ratio, together with the $\mathrm{Cl}^{-}$contents in the roots, stems, and leaves of salt-stressed PgTIP1-transgenic soybean plants exposed to salt stress, similar regulating effects were also observed as the above-mentioned PgTIP1-transformed soybean hairy roots test, particularly line J11 which performed best (Figures 6A-D). Arabidopsis plants overexpressing PgTIP1 displayed faster growth and enhanced salt stress tolerance through the enhancement of tonoplast permeability and increased water movement from the cytosol to vacuole, and greater accumulation of $\mathrm{Na}^{+}$due to the larger vacuole (Peng et al., 2007; Li and Cai, 2015). AQPs may participate in ion homeostasis at the whole plant level by regulating the ratio of apoplastic/symplastic water flow, thus directing solute flux through different plant tissues, and furthermore, it has been reported that AQPs together with $\mathrm{K}^{+}$ channels can function as plant osmo-regulators to maintain cytosolic osmolarity and increase tolerance to drought or other stresses (Wang et al., 2016). This might explain the retention of $\mathrm{Na}^{+}$and $\mathrm{Cl}^{-}$in the roots and maintenance of water content in the leaves, which conferred favorable regulation of water relation and ion homeostasis of PgTIP1-transgenic soybean plants under salt stress. In addition, oxidative damage resulting from excessive ROS is the main secondary factor, apart from osmotic and ionic stresses, influencing the plant response under saline conditions (Munns and Tester, 2008; Zhao et al., 2017). Li and Cai (2015) further showed that the leaves of PgTIP1transgenic Arabidopsis plants accumulated less $\mathrm{H}_{2} \mathrm{O}_{2}$ than WT under salt stress, which suggests that PgTIP1 transformation is also beneficial for relieving oxidative stress. In our study, when compared with WT, $\mathrm{H}_{2} \mathrm{O}_{2}$ contents in the roots and leaves of the salt-stressed PgTIP1-transgenic soybean lines $\mathrm{N}$ and J11 did not show the increase that WT did, but rather exhibited an obvious decrease. Additionally, $\mathrm{O}_{2}^{\bullet-}$ production rates rose slightly in the roots but dropped in the leaves (Figures 7A,B), which was consistent with enhanced activities of SOD, POD, CAT, and APX in the roots or leaves under salt stress (Figures 7C,D). Li and Cai (2015) suggested that the heterologous expression of PgTIP1 led to the upregulated expression of stress-related genes, such as CBF3, MYB15, COR47, $I C E 1$, etc., which could contribute to the salt tolerance of the transgenic Arabidopsis plant. In this work, we also found that the expression levels of GmPOD, GmAPX1, GmSOS1, and GmCLC1 in the roots and leaves of PgTIP-transgenic lines were also reinforced in comparison to WT, but there were no differences in the expression of endogenous soybean GmTIP1;1 and GmTIP1;3, which shared the highest homology with PgTIP1 (Figure 8). This indicates that heterologous PgTIP1 transformation into soybean has an obvious positive contribution toward salt tolerance at the transcriptional level of stress-related genes coding ion transporters and antioxidant enzymes. Xin et al. (2014) reported that, tomato SITIP2;2-transformed Arabidopsis plants exhibited enhanced salt stress tolerance, which has close links with higher $\mathrm{K}^{+} / \mathrm{Na}^{+}$ratio (for ion homeostasis) and increased SOD, CAT, and POD activities (for ROS scavenging) than the wild-type control under salt stress. Wang et al. (2014) also demonstrated that, TsTIP1;2-overexpressed Arabidopsis plants displayed strong tolerance against salt or oxidative stress through the capability of direct conducting $\mathrm{H}_{2} \mathrm{O}$, and the indirect facilitation of $\mathrm{Na}^{+}$ influx or $\mathrm{H}_{2} \mathrm{O}_{2}$ transport into the vacuoles. We also further need to seek more evidence at the subcellular level of vacuoles in future.

\section{CONCLUSION}

Firstly, the heterologous overexpression of $P g T I P 1$ resulted in the transformed soybean cotyledon hairy roots or composite plants mediated by A. rhizogenes displaying superior salt tolerance to the empty vector-transformant according to the ameliorative roles 
in hairy root growth reduction, leaf RWC drop, and REL rise of composite plants under salt stress. Additionally, a decline in $\mathrm{K}^{+}$contents, increase in $\mathrm{Na}^{+}$contents and $\mathrm{Na}^{+} / \mathrm{K}^{+}$ratios in the hairy roots, stems, or leaves were effectively mitigated by $P g T I P 1$ transformation, especially with respect to the stems and leaves of composite soybean plants. At whole plant level, pollen-tube transformation pathway PgTIP1-transgenic soybean lines possessed stronger root vigor, lighter cell membrane damage to the roots and leaves, improved SOD, POD, CAT, and APX activities along with the enhanced expression of $P O D$ and $A P X$ genes under salt treatment, steadily increased values of leaf RWC, $\mathrm{Tr}$, and $\mathrm{Pn}$, and smaller declines in chlorophyll and carotenoid contents when exposed to salt stress compared to WT. With regards to transport or distribution of salty ions in salt-stressed PgTIP1-trasgenic soybean lines, the heterologous transformation of PgTIP1 into soybean plants could readjust the distribution pattern of $\mathrm{Na}^{+}, \mathrm{K}^{+}$, and $\mathrm{Cl}^{-}$ in the roots and shoots (stems and leaves), i.e., the absorbed $\mathrm{Na}^{+}$and $\mathrm{Cl}^{-}$mainly accumulated in the roots so as to reduce their transport to the shoots, and the root-absorbed $\mathrm{K}^{+}$was simultaneously promoted to be transported toward the shoots. This may be related to PgTIP1 transformation- and salt stress-induced enhancement of the expression of GmSOS1 and GmCLC1 genes, which control $\mathrm{Na}^{+}$and $\mathrm{Cl}^{-}$into and out of

\section{REFERENCES}

Aebi, H. (1984). Catalase in vitro. Methods Enzymol. 105, 121-126. doi: 10.1016/ S0076-6879(84)05016-3

Ao, J., Li, Q., Gao, X., Yu, Y., Li, L., and Zhang, M. (2011). A multiplex nested PCR assay for the simultaneous detection of genetically modified soybean, maize and rice in highly processed products. Food Control. 22, 1617-1623. doi: 10.1016/j.foodcont.2011.03.018

Beauchamp, C., and Fridovich, I. (1971). Superoxide dismutase: improved assays and an assay applicable to acrylamide gels. Anal. Biochem. 44, 276-287. doi: 10.1016/0003-2697(71)90370-8

Boursiac, Y., Chen, S., Luu, D.-T., Sorieul, M., van den Dries, N., and Maurel, C. (2005). Early effects of salinity on water transport in Arabidopsis roots. Molecular and cellular features of aquaporin expression. Plant Physiol. 139, 790-805. doi: 10.1104/pp.105.065029

Chaumont, F., and Tyerman, S. D. (2014). Aquaporins: highly regulated channels controlling plant water relations. Plant Physiol. 164, 1600-1618. doi: 10.1104/ pp.113.233791

Danielson, J. A., and Johanson, U. (2008). Unexpected complexity of the aquaporin gene family in the moss Physcomitrella patens. BMC Plant Biol. 8:45. doi: 10.1186/1471-2229-8-45

Deshmukh, R. K., Sonah, H., and Bélanger, R. R. (2016). Plant Aquaporins: genome-wide identification, transcriptomics, proteomics, and advanced analytical tools. Front. Plant Sci. 7:1896. doi: 10.3389/fpls.2016.01896

Dietz, K.-J., Mittler, R., and Noctor, G. (2016). Recent progress in understanding the role of reactive oxygen species in plant cell signaling. Plant Physiol. 171, 1535-1539. doi: 10.1104/pp.16.00938

Elstner, E. F., and Heupel, A. (1976). Inhibition of nitrite formation from hydroxylammoniumchloride: a simple assay for superoxide dismutase. Anal. Biochem. 70, 616-620. doi: 10.1016/0003-2697(76)90488-7

Guo, L., Wang, Z. Y., Lin, H., Cui, W. E., Chen, J., Liu, M. H., et al. (2006). Expression and functional analysis of the rice plasma-membrane intrinsic protein gene family. Cell Res. 16, 277-286. doi: 10.1038/sj.cr. 7310035

Hu, S. B., Zhou, Q., An, J., and Yu, B. J. (2016). Cloning PIP genes in droughttolerant vetiver grass and responses of transgenic VzPIP2;1 soybean plants to water stress. Biol. Plant. 60, 655-666. doi: 10.1007/s10535-016-0631-5 the cell, and the transport and intracellular compartmentation of soybean plants. Finally, these results reveal that the cause of enhanced salt tolerance of heterologous PgTIP1-transformed soybeans lies in its positive regulation of water relations, ion homeostasis, and ROS scavenging under salt stress both at the root-specific and whole plant levels. Therefore, PgTIP1 can be considered as a good candidate gene for the production of new salt tolerant plant germplasms and crop cultivars in the future.

\section{AUTHOR CONTRIBUTIONS}

$\mathrm{JA}, \mathrm{ZH}$, and $\mathrm{HC}$ conducted the experiments, collected and analyzed all data. BY and WC designed the experiments. BY, $\mathrm{JA}$, and $\mathrm{BC}$ interpreted the data and wrote the manuscript. All authors read and approved the final version of the manuscript.

\section{FUNDING}

This work was supported by the Transgenic Engineering Crops Breeding Special Funds of China (No. 2009ZX08004-008B) awarded to BY and WC.

Kaldenhoff, R., and Fischer, M. (2006). Functional aquaporin diversity in plants. Biochim. Biophys. Acta 1758, 1134-1141. doi: 10.1016/j.bbamem.2006.03.012

Katsuhara, M., Hanba, Y. T., Shiratake, K., and Maeshima, M. (2008). Expanding roles of plant aquaporins in plasma membranes and cell organelles. Funct. Plant Biol. 35, 1-14. doi: 10.1071/FP07130

Katsuhara, M., Koshio, K., Shibasaka, M., Hayashi, Y., Hayakawa, T., and Kasamo, K. (2003). Over-expression of a barley aquaporin increased the shoot/root ratio and raised salt sensitivity in transgenic rice plants. Plant Cell Physiol. 44, 1378-1383. doi: 10.1093/pcp/pcg167

Li, H., and Wu, T. L. (2007). Transforming Agrobacterium into soybean by means of pollen tube pathway induced by $\mathrm{CaCl}_{2}$. Soybean Sci. 26, 55-59.

Li, J., and Cai, W. M. (2015). A ginseng PgTIP1 gene whose protein biological activity related to $\mathrm{Ser}^{128}$ residue confers faster growth and enhanced salt stress tolerance in Arabidopsis. Plant Sci. 234, 74-85. doi: 10.1016/j.plantsci.2015. 02.001

Li, W. Y., Wong, F.-L., Tsai, S.-N., Shao, G. H., and Lam, H.-M. (2006). Tonoplastlocated GmCLC1 and GmNHX1 from soybean enhance $\mathrm{NaCl}$ tolerance in transgenic bright yellow (by)-2 cells. Plant Cell Environ. 29, 1122-1137. doi: 10.1111/j.1365-3040.2005.01487.x

Lin, W., Peng, Y., Li, G., Arora, R., Tang, Z., Su, W., et al. (2007). Isolation and functional characterization of PgTIP1, a hormone-autotrophic cells-specific tonoplast aquaporin in ginseng. J. Exp. Bot. 58, 947-956. doi: 10.1093/jxb/erl255

Manavalan, L. P., Guttikonda, S. K., Tran, L.-S. P., and Nguyen, H. T. (2009). Physiological and molecular approaches to improve drought resistance in soybean. Plant Cell Physiol. 50, 1260-1276. doi: 10.1093/pcp/pcp082

Maurel, C., Verdoucq, L., Luu, D. T., and Santoni, V. (2008). Plant Aquaporins: membrane channels with multiple integrated functions. Annu. Rev. Plant Biol. 59, 595-624. doi: 10.1146/annurev.arplant.59.032607.092734

Moore, S., Croughan, T., Myers, G., and Vidrine, R. (1996). Investigation of transferring the BAR gene into soybean via the pollen tube pathway. Soybean Genet. Newsl. 23, 167-168.

Munns, R., and Tester, M. (2008). Mechanisms of salinity tolerance. Annu. Rev. Plant Biol. 59, 651-681. doi: 10.1146/annurev.arplant.59.032607.092911

Nakano, Y., and Asada, K. (1981). Hydrogen peroxide is scavenged by ascorbate specific peroxidase in spinach chloroplasts. Plant Cell Physiol. 22, 867-880.

Peng, Y., Lin, W., Cai, W., and Arora, R. (2007). Overexpression of a Panax ginseng tonoplast aquaporin alters salt tolerance, drought tolerance and cold 
acclimation ability in transgenic Arabidopsis plants. Planta 226, 729-740. doi: 10.1007/s00425-007-0520-4

Perrone, I., Gambino, G., Chitarra, W., Vitali, M., Pagliarani, C., Riccomagno, N., et al. (2012). The grapevine root-specific aquaporin $V v P I P 2 ; 4 N$ controls root hydraulic conductance and leaf gas exchange under well-watered conditions but not under water stress. Plant Physiol. 160, 965-977. doi: 10.1104/pp.112.203455

Qu, Y. N., Zhou, Q., and Yu, B. J. (2009). Effects of $\mathrm{Zn}^{2+}$ and niflumic acid on photosynthesis in Glycine soja and Glycine max seedlings under $\mathrm{NaCl}$ stress. Environ. Exp. Bot. 65, 304-309. doi: 10.1016/j.envexpbot.2008.11.005

Rouached, H., Pal, S., Rachmilevitch, S., Libault, M., and Tran, L.-S. P. (2015). Plants coping abiotic and biotic stresses: a tale of diligent management. Biomed. Res. Int. 2015:754754. doi: 10.1155/2015/754754

Sade, N., Gebretsadik, M., Seligmann, R., Schwartz, A., Wallach, R., and Moshelion, M. (2010). The role of tobacco Aquaporin1 in improving water use efficiency, hydraulic conductivity, and yield production under salt stress. Plant Physiol. 152, 245-254. doi: 10.1104/pp.109.145854

Saxena, I., Srikanth, S., and Chen, Z. (2016). Cross talk between H2O2 and interacting signal molecules under plant stress response. Front. Plant Sci. 7:570. doi: $10.3389 /$ fpls.2016.00570

Sergiev, I., Alexieva, V., and Karanov, E. (1997). Effect of spermine, atrazine and combination between them on some endogenous protective systems and stress markers in plants. Compt. Rend. Acad. Bulg. Sci. 51, 121-124.

Siefritz, F., Tyree, M. T., Lovisolo, C., Schubert, A., and Kaldenhoff, R. (2002). PIP1 plasma membrane aquaporins in tobacco: from cellular effects to functions in plants. Plant Cell 14, 869-876. doi: 10.1105/tpc.000901

Song, L., Nguyen, N., Deshmukh, R. K., Patil, G. B., Prince, S. J., Valliyodan, B., et al. (2016). Soybean TIP gene family analysis and characterization of GmTIP1;5 and GmTIP2;5 water transport activity. Front. Plant Sci. 7:1564. doi: 10.3389/fpls. 2016.01564

Srivastava, A. K., Penna, S., Nguyen, D. V., and Tran, L. P. (2014). Multifaceted roles of aquaporins as molecular conduits in plant responses to abiotic stresses. Crit. Rev. Biotechnol. 36, 389-398. doi: 10.3109/07388551.2014.973367

Tian, F., Jia, T. J., and Yu, B. J. (2014). Physiological regulation of seed soaking with soybean isoflavones on drought tolerance of Glycine max and Glycine soja. Plant Growth Regul. 74, 229-237. doi: 10.1007/s10725-014-9914-z

Tian, S., Wang, X., Li, P., Wang, H., Ji, H., Xie, J., et al. (2016). Plant aquaporin AtPIP1;4 links apoplastic $\mathrm{H}_{2} \mathrm{O}_{2}$ induction to disease immunity pathways. Plant Physiol. 171, 1635-1650. doi: 10.1104/pp.15.01237

Wang, C. J., Yang, W., Wang, C., Gu, C., Niu, D. D., Liu, H. X., et al. (2012). Induction of drought tolerance in cucumber plants by a consortium of three plant growth-promoting rhizobacterium strains. PLOS ONE 7:e52565. doi: 10.1371/journal.pone.0052565

Wang, L. L., Chen, A. P., Zhong, N. Q., Liu, N., Wu, X. M., Wang, F., et al. (2014). The Thellungiella salsuginea tonoplast aquaporin TsTIP1;2 functions in protection against multiple abiotic stresses. Plant Cell Physiol. 55, 148-161. doi: $10.1093 / \mathrm{pcp} / \mathrm{pct} 166$
Wang, M., Ding, L., Gao, L., Li, Y., Shen, Q., and Guo, S. (2016). The interactions of aquaporins and mineral nutrients in higher plants. Int. J. Mol. Sci. 17:E1229. doi: 10.3390/ijms17081229

Wang, X., Li, Y., Ji, W., Bai, X., Cai, H., Zhu, D., et al. (2011). A novel Glycine soja tonoplast intrinsic protein gene responds to abiotic stress and depresses salt and dehydration tolerance in transgenic Arabidopsis thaliana. J. Plant Physiol. 168, 1241-1248. doi: 10.1016/j.jplph.2011.01.016

Wei, P., Chen, D., Jing, R., Zhao, C., and Yu, B. (2015). Ameliorative effects of foliar methanol spraying on salt injury to soybean seedlings differing in salt tolerance. Plant Growth Regul. 75, 133-141. doi: 10.1007/s10725-014-9938-4

Wei, P., Wang, L., Liu, A., Yu, B., and Lam, H.-M. (2016). GmCLC1 confers enhanced salt tolerance through regulating chloride accumulation in soybean. Front. Plant Sci. 7:1082. doi: 10.3389/fpls.2016.01082

Wudick, M. M., Luu, D.-T., and Maurel, C. (2009). A look inside: localization patterns and functions of intracellular plant aquaporins. New Phytol. 184, 289-302. doi: 10.1111/j.1469-8137.2009.02985.x

Xin, S., Yu, G., Sun, L., Qiang, X., Xu, N., and Cheng, X. (2014). Expression of tomato SITIP2;2 enhances the tolerance to salt stress in the transgenic Arabidopsis and interacts with target proteins. J. Plant Res. 127, 695-708. doi: 10.1007/s10265-014-0658-7

Zhang, D. Y., Ali, Z., Wang, C. B., Xu, L., Yi, J. X., Xu, Z. L., et al. (2013). Genomewide sequence characterization and expression analysis of major intrinsic proteins in soybean (Glycine max L.). PLoS ONE 8:e56312. doi: 10.1371/journal. pone. 0056312

Zhang, X. K., Zhou, Q. H., Cao, J. H., and Yu, B. J. (2011). Differential $\mathrm{Cl}^{-} /$salt tolerance and $\mathrm{NaCl}$-induced alternations of tissue and cellular ion fluxes in Glycine max, Glycine soja and their hybrid seedlings. J. Agron. Crop Sci. 197, 329-339. doi: 10.1111/j.1439-037X.2011.00467.x

Zhao, X., Wei, P., Liu, Z., Yu, B., and Shi, H. (2017). Soybean $\mathrm{Na}^{+} / \mathrm{H}^{+}$antiporter GmsSOS1 enhances antioxidant enzyme activity and reduces $\mathrm{Na}^{+}$accumulation in Arabidopsis and yeast cells under salt stress. Acta Physiol. Plant. 39:19. doi: $10.1007 / \mathrm{s} 11738-016-2323-3$

Zhou, Q., and Yu, B. J. (2009). Accumulation of inorganic and organic osmolytes and its role in osmotic adjustment in $\mathrm{NaCl}$-stressed vetiver grass seedlings. Russ. J. Plant Physiol. 56, 678-685. doi: 10.1134/S1021443709050148

Conflict of Interest Statement: The authors declare that the research was conducted in the absence of any commercial or financial relationships that could be construed as a potential conflict of interest.

Copyright (C) $2017 \mathrm{An}, \mathrm{Hu}$, Che, Chen, Yu and Cai. This is an open-access article distributed under the terms of the Creative Commons Attribution License (CC BY). The use, distribution or reproduction in other forums is permitted, provided the original author(s) or licensor are credited and that the original publication in this journal is cited, in accordance with accepted academic practice. No use, distribution or reproduction is permitted which does not comply with these terms. 